\title{
Metabiotics: The Functional Metabolic Signatures of Probiotics: Current State-of-Art and Future Research Priorities
}

-Metabiotics: Probiotics Effector Molecules

\author{
Aarti Singh, Vishakha Vishwakarma, Barkha Singhal* \\ School of Biotechnology, Near Kasna Road, Gautam Buddha University, Greater Noida (U.P.), India \\ Email: drasingh94@gmail.com, vishakha.v96@gmail.com, *barkha@gbu.ac.in, ‘gupta.barkha@gmail.com
}

How to cite this paper: Singh, A., Vishwakarma, V. and Singhal, B. (2018) Metabiotics: The Functional Metabolic Signatures of Probiotics: Current State-of-Art and Future Research Priorities-Metabiotics: Probiotics Effector Molecules. Advances in Bioscience and Biotechnology, 9, 147-189.

https://doi.org/10.4236/abb.2018.94012

Received: February 28, 2018

Accepted: April 25, 2018

Published: April 28, 2018

Copyright $\odot 2018$ by authors and Scientific Research Publishing Inc. This work is licensed under the Creative Commons Attribution International License (CC BY 4.0).

http://creativecommons.org/licenses/by/4.0/

\section{(c) (i) Open Access}

\begin{abstract}
The intricate "orchestered molecular conversation" between the host and gut microbiome is one of the most dynamic research areas in recent years. The rhythmic chemical cross talk in the form of bioactive metabolites and signalling molecules synthesized by gut microbiome plays a significant role for the modulation of human health in diversified ways. They are recognized as low molecular weight (LMW) molecules having versatile chemical attributes. They possess magnificent capability of interacting with surrounding environment and controlling the genes for various genetic, biochemical and physiological functions for maintaining the homeostasis that is now-a-days termed as "small molecules microbes originated (SMOM) homeostasis" in the host. These metabolic signatures have close structural and functional resemblance with small molecules synthesized by host eukaryotic cells and dietary components. Therefore, they may be considered as universalized metabolites contributing to the remarkable phenomenon of epigenetic regulation, cell to cell communication and stability of genome manifesting the overall growth and development of the host and known as "metabiotics". The wide panorama of utilization of probiotics is continuously expanding and conferring the major health benefits through metabiotic components are gaining tremendous momentum therefore recognized as "hidden soldiers" of the body. Therefore firstly, we outline the need and types of metabiotic molecules and depicting their role in human health. Then, we summarize their preventive and therapeutic avenues in various diseases and finally, we propose the current technological interventions, bottlenecks and future perspectives in this field that are implied for accelerating their comprehensive understanding and utilization at industrial scale.
\end{abstract}




\section{Keywords}

Metabiotics, Probiotics, Metabolic Signatures, Gut Microbiome, Homeostasis

\section{Introduction}

The past decade revolutionizes the concept of humans as "superorganism" due to the presence of a myriad of microbial communities in the gut that leads to impart the significant beneficial implications on the well-being of human health [1]. This microbial consortium constitutes of various representatives of bacteria, archaea, viruses and fungi representing themselves as a highly complex ecosystem. The hierarchical evolutionary relationship leads to the mutualistic relationship between the host and microbiome which gradually attains dynamism for controlling and coordinating the immune response, entire genetic and metabolic signaling and overall health status of the host [2]. Figure 1 representing the various microbiomes present in the human body [3] [4] [5] [6] [7]. Among, the astounding array of microbial world, probiotics emerges as one of the widely acknowledged GRAS organisms utilized for the manipulation of gut microbiota for health benefits. The impressive potentially probiotics has been assessed in terms of health benefits, but the dilemmatic situation has been existed due to the risk associated with the consumption of probiotics due to their multiple mechanism of action which are dependent on specificity of strain and species utilized [8]. Therefore, substantial efforts are required for thorough understanding of their positive interplay with the host as well as other gut microbial systems at the molecular level [9]. Research studies confirmed that there is fine choreographed molecular networking between the host and probiotics in the form of small "molecular cues". They can significantly affect the entire microbiome as well as host physiology, metabolism and signaling pathways and their dynamic

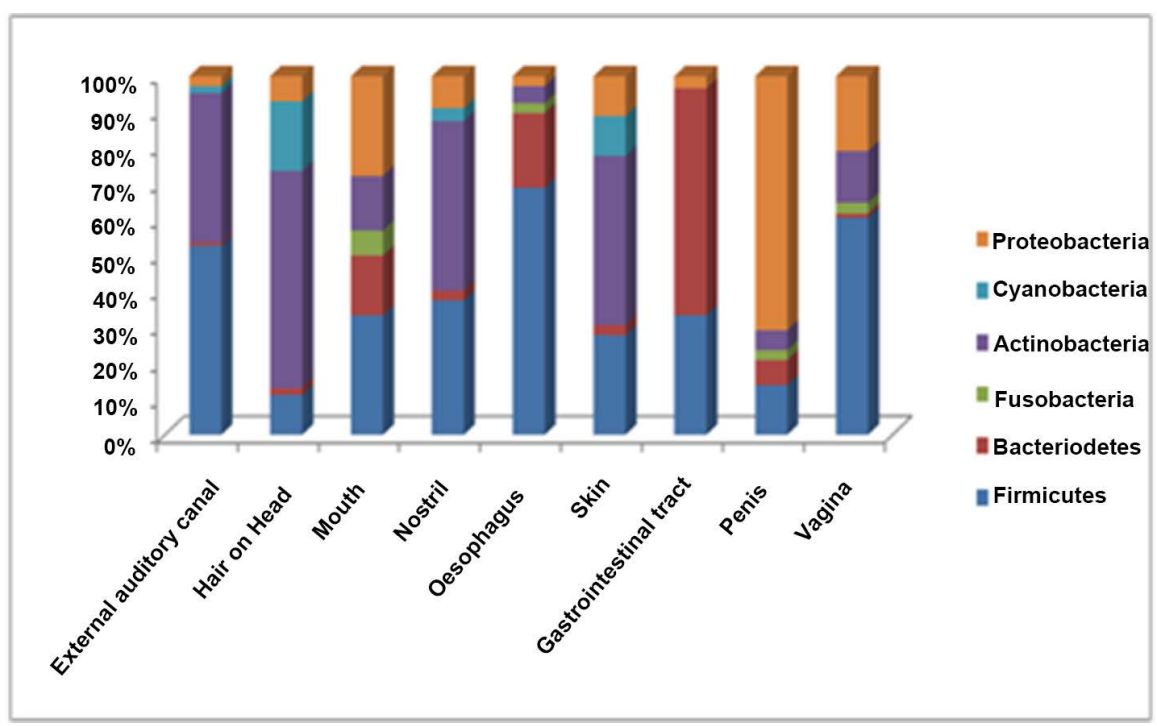

Figure 1. Overview of percentage of various microbiome in the human body. 
control has been visualized on genetic framework from epigenetics to biochemical level [10] [11]. In the entire army of immune system of host they are acting as the "hidden soldiers" for the body. These "hidden soldiers" have been designated as "metabotics", "biological drugs" [12], "biogenics", "CFS" (Cell free supernatants) "postbiotics" [13], "heat-killed probiotic" [14] or "pharmacobiotics" [15]. Though, the studies on various structural and functional aspects of metabiotics are in infancy but the continuum towards comprehensive studies paved the way for personalized molecular bio-therapeutic avenue for designing of novel metabiotics with enhanced health benefits. Therefore, the present review addresses the emerging information of the molecular cross-talk of different probiotic's metabolic signatures for their beneficial health implications. Though applications of metabiotics have opened a novel avenue for the development of designer probiotics but contain numerous technological challenges. Therefore, considerable focus has been given for the areas of current progress and challenges as well as future perspectives for the effective implementation of metabiotics.

\section{Characteristics of Metabiotics}

The various research investigations of last twenty years speculated that gut microorganisms have remarkable ability to synthesize, detect and respond to different LMW bio-active molecules by metabolizing various endogenous and exogenous (dietary components) substrates [10] [16]. They are structurally diverse molecules either diffusible into the body fluids or permeable to the intestinal membrane and sometimes it requires specific receptors at the cell surface for their inception into the body. They act locally and systemic level to impart their beneficial effects by modulating the physiological and metabolic parameters in the host cell. They may be exclusive signaling molecules, metabolites or molecules comprising metabolic or signalling activity simultaneously [11]. Figure 2 summarizes the characteristics of metabiotics. Recent investigations revealed that these molecules composed of different chemical structures and different origins but have possibility of same targets for their action. They act synergistically by expressing structural and regulatory genes for both microbial as well as host cells coordinating the positive interplay between host/microbe and microbe/microbe cross talk. They also regulate the metagenome stability, post-translation modification of gene products and epigenetic regulation to maintain the general health of an individual. Therefore, the enormous potentiality of these hidden molecules can be manifested for the improvement in functionality and bioavailability of probiotics and other beneficial gut microbes [10] [11].

\section{Mechanism of Action of Metabiotics}

The potential therapeutic role conferred by metabioitcs leads to the paradigmatic shift in the studies emerging in this direction. Though the studies are at their early stage of infancy it will take more time to completely unravel their potential 


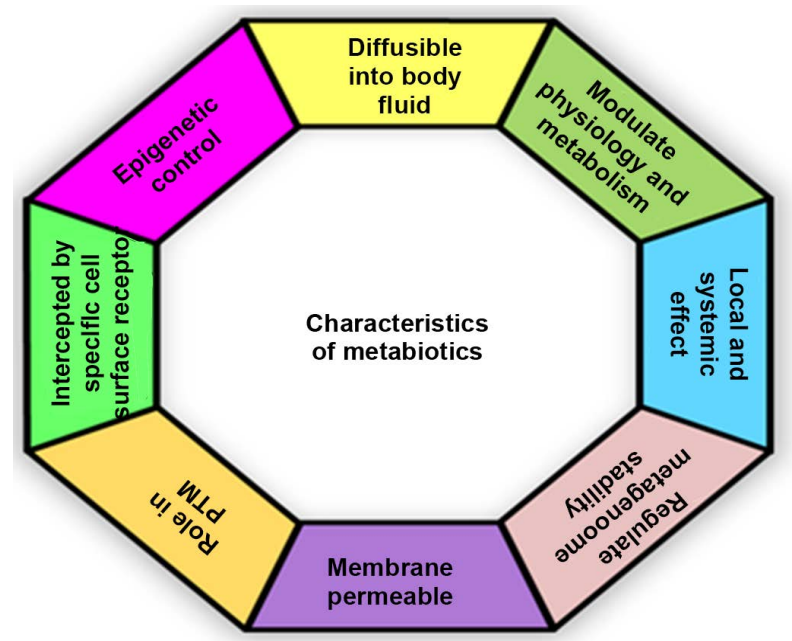

Figure 2. Characteristics of metabiotics.

mechanism of action. The overwhelming studies hypothesized that the diversified biological function of metabiotics may be a result of epigenetic modifications that subsequently affect various biochemical and signaling pathways leads to the positive modulation in various physiological process of the host. The various epigenetic processes like DNA methylation, phosphorylation, biotinylation, histone acetylation and RNA interference has been involved for carrying out the epigenetic control of the host cell responses [17] [18]. These modifications confers significant effect on various biochemical process like immunomodulation, competitive exclusion, regulating epithelial cell barrier function, interfering quorum sensing molecules. Further these biochemical modifications can lead to exert their beneficial role in the prevention of various deadly diseases like, cancers, IBD, auto-immune disorders, life style disorders etc. [19]. The overview of their mechanism of action has been represented in Figure 3.

\section{Types of Metabiotics}

The potential health benefits of probiotics have been documented in a plethora of research publications till date. The current knowledge accumulated for understanding the mode of action of probiotics has been possible by studying their molecular languages as metabiotic components. Various low molecular weight (LMW) molecules of different chemical manifestations have been visualized for their devastating health implications [20]. They are composed of wide arena of molecules including bacteriocines, SCFAs, surface and exogenous proteins, polysaccharides, lectins, miRNA, amino acids, lactones, quorum sensing signals, anti-oxidants, vitamins, serpins, NO and receptors for adhesion, GABA etc. [10] [11] [21]. The detailed overview of these metabiotic is shown in Figure 4 components is mentioned below:

\subsection{Shot Chain Fatty Acids (SCFAs)}

They are classified as metabolic end products released by utilizing the complex non-digestible carbohydrates as substrates though gut microbial fermentation 


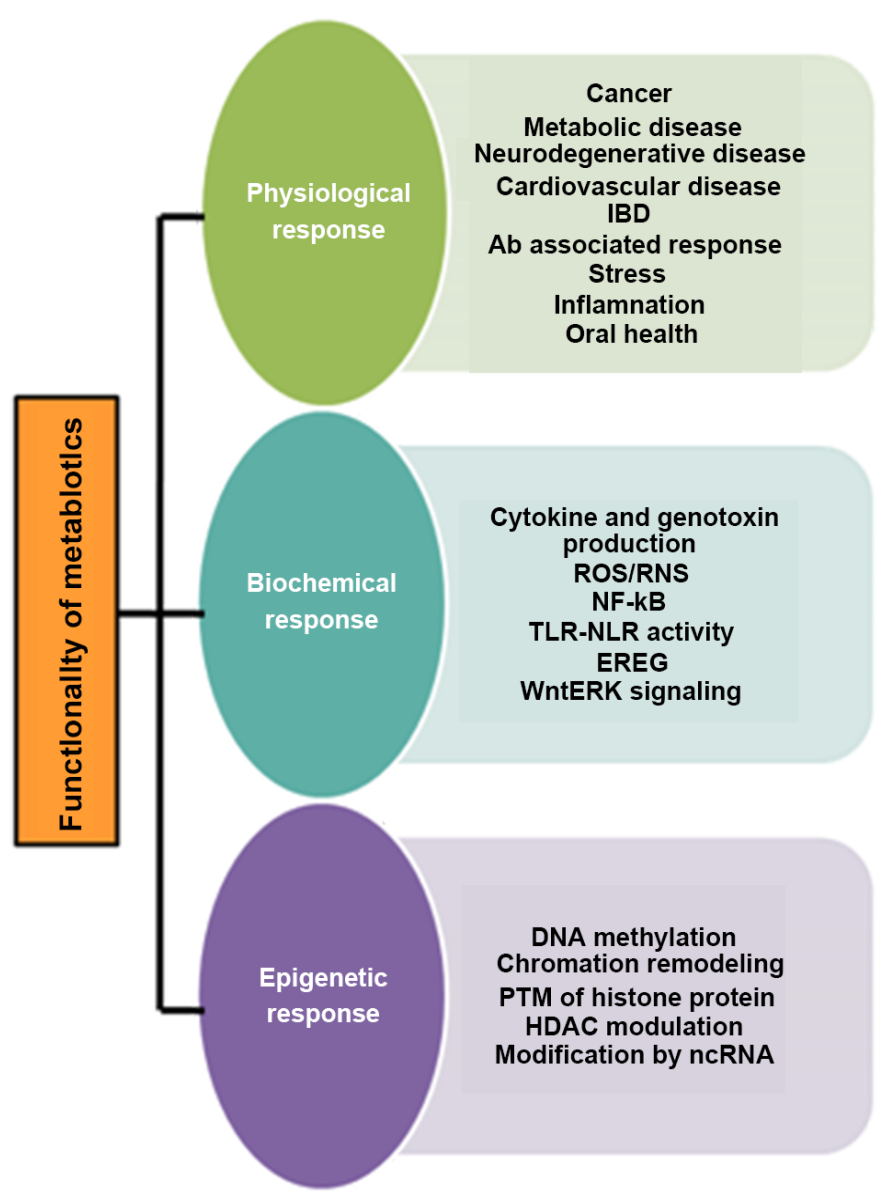

Figure 3. Mechanism of action of metabiotics.

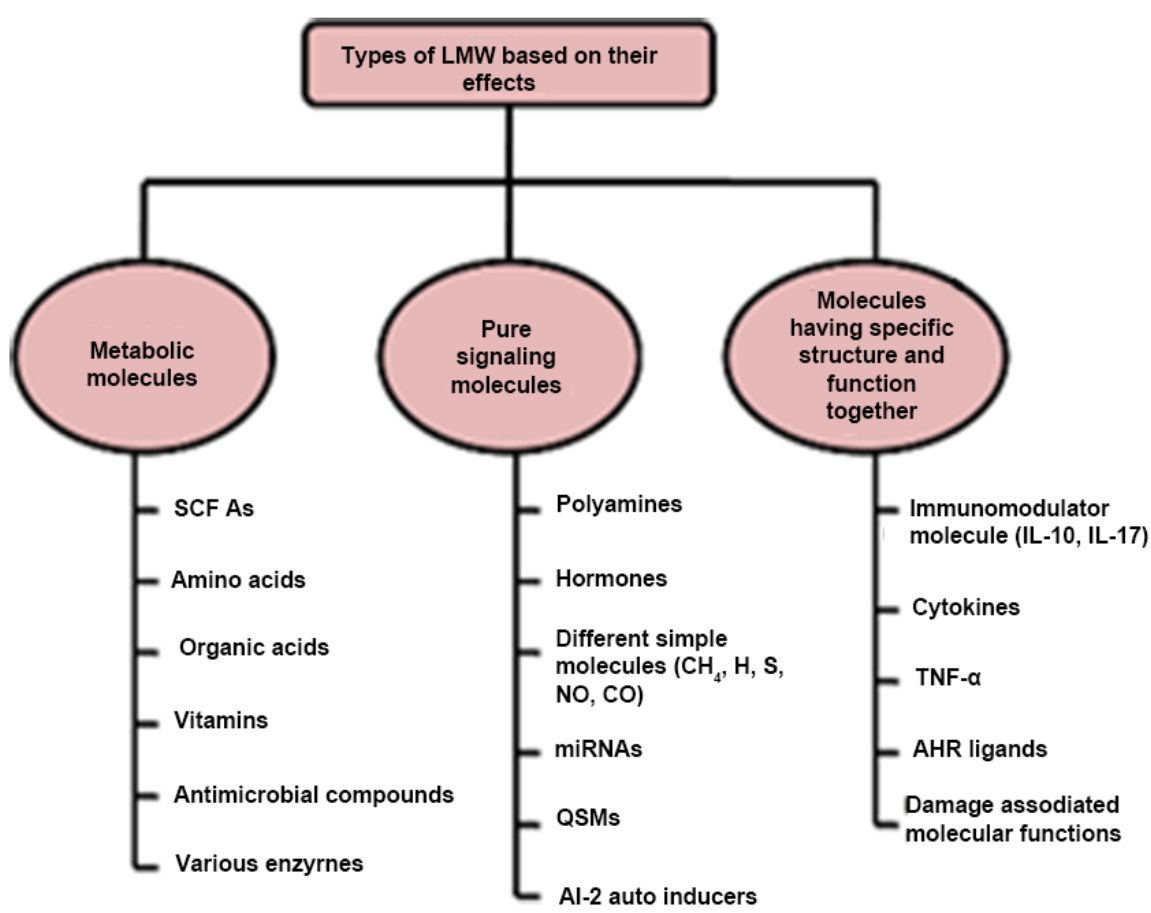

Figure 4. Types of metabiotics. 
process [22]. These molecules are known as short-chain fatty acids (SCFAs), including lactic acid, propionic acid, acetic acid, succinic acid and butyric acid [23]. The structures of various SCFAs are depicted in Figure 5. The concentration of SCFA in the gut lumen varies between $20-140 \mathrm{mM}$ due to microbial composition, fiber rich dietary molecules and intestinal retention time of the microbial populations. They are acting as excellent energy sources for the gut microbiome as well as intestinal epithelial cells and perform various regulatory functions in maintaining the physiology and immunity of the host cells [24]. Therefore, nowadays they are recognized as important category of therapeutic molecules and represented themselves as "epigenetic drugs" as anti-cancer and anti-inflammatory agents [25] [26]. They also perform the function of signaling molecules by acting the ligands for ligands for $G$ protein-coupled receptors (GPCRs) and inhibitors of histone deacetylases (HDACs) [22] [23]. They are acting as positive modulator for the treatment of antibiotic-associated diarrhea, crohn's disease, ulcerative colitis, obesity and cholesterol reduction. These molecules have been successfully applied for the therapeutic intervention of treatment of various inflammatory disorders and also help in alleviation of insulin resistance and obesity [27]. Though the exact mechanism of their action is yet to be fully elucidated but their capability of modifying the epigenome will drive the more comprehensive understanding of their health promoting attributes.

\subsubsection{Polyamines}

These are polycationic and highly reactive molecules ubiquitously present in all living cells [28]. They are the manifestations of the dietary interventions as well as synthesized by host and gut microbial cells. They are deployed for variety of biological functions affecting the phenomenon of transcription to translation as well as cellular differentiation to cellular death. These include molecules such as putrescine, spermidine and spermine molecules and their metabolism plays a central role in the immunomodulation [29]. The structures of putrescine, spermidine and spermine are depicted in Figure 6. Therefore, their synthesis must be stringently controlled by the host through different regulatory mechanisms. They mediate the function of maintaining the integrity of the IEC barrier by stimulating the production of intercellular junction proteins like zonula occludens 1 (ZO1; also known as TJP1), occludin and E-cadherin (also known as cadherin 1) [30]. Research studies also elucidated their considerable role in colorectal, skin, prostrate, and breast cancer and various inflammatory disorders [31]. They plays considerable role in maintaining the adaptive and mucosal immunity. The aberrations in polyamine metabolism lead to the devastating effect on the neurological behavior of the host. Various research studies have demonstrated that there is synergism between the polyamines derived from host as well as bacteria that promote the well-being of the host cell however, perturbations in their metabolism influences the health of the host is still the matter of intensive investigations. 
<smiles>CC(O)C(=O)O</smiles>

(a) Lactic acid<smiles>CC(=O)O</smiles>

(c) Acetic acid

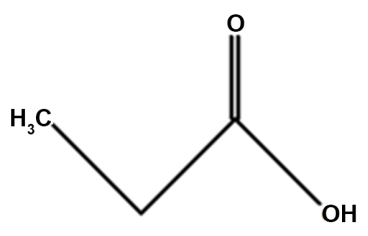

(b) Propionic acid<smiles>O=C(O)CCC(=O)O</smiles>

(d) Sucinic acid<smiles>CCCC(=O)O</smiles>

(e) Butyric acid

Figure 5. Structures of various Short Chain Fatty Acids.<smiles>NCCCCN</smiles>

(a) Putrescine<smiles>NCCCCNCCCN</smiles>

(b) Spermidine<smiles>NCCCNCCCCNCCCN</smiles>

(c) Spermine

Figure 6. Structures of various Polyamines.

\subsubsection{Bacteriocins}

Bacteriocins are heterogeneous group of anti-microbial peptides produced by all lineages of archaea and bacteria. The common examples of bacteriocin producing bacteria are E. coli, C. freundii, L.acidophilus, L. casei, L. plantarum, Halobacteria.Their physical and chemical varsities leads to the different types of bacteriocins in terms of molecular size, target cell receptors, mode of action, heat 
and temperature stability and immunity mechanisms [32]. The production of bacteriocins has been considered as an essential trait for the selection of probiotic strains for the inhibition of pathogens and considered as potential food preservative but nowadays intriguing evidence indicated that these molecules may function in diversified ways in the gastrointestinal tract. In the recent experimental studies, it was shown that the bacteriocin produced from Lactobacillus salivarius UCC118 was able to modulate the microbiota of gastro-intestinal tract in diet-induced obese mice, while no such changes were observed in its bacteriocin-free derivative thereby confirming their potential role in health promoting activity and positive modulation of gut microbiome [33]. Owing to their anti-microbial nature, the current intervention of nanotechnology and genetic engineering leads to the new possibilities for consideration of bacteriocins as "next generation antibiotics" [34]. These molecules opened the exciting field for novel drug delivery systems for the treatment of cancer as well as play a significant role in the regulation of quorum sensing phenomenon in gut microbial ecosystem. Some bacteriocins like subtilosin A from Bacillus subtilis have been reported to possess the anti-viral and spermicidal activities [35]. A variety of other anti-microbial actions have been documented for the various probiotics species to combat infections like urogenital tract infections [36] [37], Clostridium [38], L.monocytogenes [39] [40], candidiasis and mastitis infection [41], gastrointestinal and pneumococcal infections [42] [43]. Tough the food preservation has been considered the major application of the bacteriocins but growing knowledge regarding their structural and functional diversity leads to various attempts for elucidating either the more comprehensive functions or improves the functionality of these molecules nowadays [44].

\subsubsection{Cell Surface Molecules}

The cell surface architecture of probiotic constitutes various surface-active molecules like polysaccharides, surface layer proteins, pilli, fimbriae and flagella. The surface properties of these micro-organisms depend on various environmental conditions that are likely to affect the compositional, organizational and conformational changes at the bacterial cell surface and are consequently affecting various health modulating properties [45]. Now-a-days numerous attempts have been undertaken for in-depth understanding of their metabiotic implications as health promoting activities that at some extent solve the quest for dynamicity of the action of gut microbiome. The various metabiotic properties of cell surface molecules are mentioned here under:

\subsubsection{Polysaccharides}

The most varied macromolecule which is present at the bacterial cell surface is polysaccharides and their major functions have been ascribed for maintaining microbial integrity and survival. These include structural polysaccharides constituting cell wall components, viz. lipopolysaccharides (LPSs), peptidoglycans, lipotechoic acids and capsular polysaccharides (CPSs) that are covalently bonded 
with cell surface or secreted into the extracellular environment in the form of exopolysaccharides (EPSs). Currently, the research studies confirmed that EPS plays an important role in bacterial adhesion properties and acts as anti-bacterial, anti-tumor and anti-inflammatory molecules by the modulation of immune cells. Recently, EPS produced by the Lactobacillus species have been visualized to alleviate the experimental colitis in a dose-dependent manner [46]. Similarly, amelioration of the collagen induced arthritis has also been reported by the EPS from L. rhamnosus KL37 [47]. Moreover, EPS from Lactobacillus strains (L. reuteri 115, L. johnsonii 142, L. animalis 148) and Bifidobacterium longum 35,624 have been reported to induce the cytokine production from the macrophages confirming their role as anti-inflammatory molecules. Similarly, capsular polysaccharides (CPS) produced by Bacteroides fragilis has been reported to confer modulatory effects on innate and adaptive immunity. The most distinct polysaccharide is PSA and has been found to regulate the imbalance between (TH1) cells and TH2 cells in gnotobiotic mouse model [48]. It also suppresses inflammation by inducing the production of IL-10 by activated CD4+ $\mathrm{T}$ cells in the preclinical models of colitis. Moreover, lipoteichoic acids (LTA), structurally diversified polysaccharide possesses various immuno-regulatory properties. It confers strong anti-inflammatory effect by activating macrophages and dendritic cells (DCs) through Toll like receptors (TLR2) [49]. In addition to that, "wonder wall" of bacteria known as peptidoglycan (PG) also possess health promoting attributes. The anti-colon cancer activity was demonstrated by the peptidoglycan of L.paracasei subsp. paracasei X12 (X12-PG) [50]. Similarly, the alleviation of chronic intestinal inflammation has been observed by the polysaccharide-peptidoglycan complex (PSPG) of L.casei subsp. shirota [51]. Moreover, the integrity and survival of intestinal epithelial cells were maintained by peptidoglycans of probiotic L. rhamnosus GG viz., Msp1 (p 75) and Msp2 (p 40), in pro-inflammatory conditions [52]. Therefore, probiotic originated polysaccharides have diversified metabiotic effects but still need more detailed investigations.

\subsubsection{Surface Layer Proteins}

Surface layer proteins is one of the important constituent of the outermost cell envelope structures found on the surface of Lactobacillus and other probiotic bacterial species. They are manifested to regulate various signaling pathways and cellular process that leads to the devastating effects on the genetic expression and beneficial modulation on the physiology of the cells [53]. Research studies speculated that variety of effector molecules in the form of cytokines or antibacterial peptides (defensins), chemokines, pseudopods, mucins etc. has been induced by the surface layer proteins. Their significant role in the adhesion to gastrointestinal mucosa and subsequent modulation of immune systems has been well established. Among the wide arena of these proteins, only a few of them have been experimentally characterized till date. Further exhaustive studies are needed to identify these proteins and their positive implications at molecular level. 


\subsubsection{Pilli, Fimbriae and Flagella}

These are defined as long proteinaceous extracellular appendages extending from the bacterial surface and play significant role in adhesion, biofilm formation and host colonization. Recently the key adhesion protein of the L. rhamnosus $\mathrm{GG}$ pilus, $\mathrm{SpaC}$ has been demonstrated to show strong binding with two extracellular proteins i.e .mucin and collagen as well as promote bacterial aggregation phenomenon [54]. Similarly, the strong adhesion ability has been shown by the pili of L. lactis to intestinal epithelial cells (Caco-2) [55]. Therefore, in a nut shell, as surface protruding molecules they play vital role in the adhesion of probiotic species to their respective host cells and promotes immuno-modulatory functions.

\subsubsection{Neurotransmitters}

The gut microbiome has been symbiotically associated with the host early in the life and underwent rigorous process of development throughout the life span. The role of neuroactive compounds produced by the gut microbiome for modulating the neuronal signaling within the enteric nervous system that consequently affects the signaling in brain correlating the gut-brain axis has been currently unraveled. A wide spectrum of neuro-stimulating compounds is produced by microbial fraternity that mediates the neurodevelopment and leads to the positive mental health outcomes throughout the life span. For example, $\gamma$-aminobutyric acid (GABA) acts as the major inhibitory neurotransmitter and secreted by Lactobacillus spp. and Bifidobacterium spp. improves the protein synthesis, concentration of growth hormones in the brain and regulate the lipid levels in serum [56]. Another neuroactive molecule produced by Escherichia spp. and Bacillus spp. is nor-epinephrine that regulates the cognitive, motor and endocrine control in the host cell [57]. Furthermore, serotonin, a major neurotransmitter that controls the "emotional overhaul" that is produced by Streptococcus, Enterococcus, Lactococcus, Escherichia, and Lactobacillus species [58]. In addition to that, acetycholine that is secreted by Lactobacillus and Bacillus species is responsible for major functions related to memory and learning. Moreover, histamine produced by Streptococcus, Lactobacillus, Lactococcus, and Enterococcus species imparts significant role in sleep related disorders while dopamine produced by Escherichia, Bacillus, Lactobacillus, Streptoococcus species affects the neuronal signaling in depression, anxiety, parkinson's disease and alzheimer disease [59]. Though the expanding knowledge regarding the protective neuro-modulatory role has been envisaged nowadays but still lots of efforts are required for exploring the capacity of microbial inhabitants as factories for the production of neuro-active metabolites.

\subsubsection{Long Chain Fatty Acids (LCFA)}

The major structural component of the lipid bilayer of the plasma membrane of neuron is long-chain fatty acids (LC-PUFAs) that includes arachidonic acid (AA, C20:4n-6) and docosahexaenoic acid (DHA, C22:6n-3) plays vital role in neurotransmission. These are important fatty acids for neurological develop- 
ment and affects regulation of ion channels and neuro-receptors. Research studies reported that administration of probiotics like Bifidobacterium breve strain, B. breve NCIMB702258 imparted significant effect on the composition of fatty acid in brain [60]. In addition to that, several research investigations supported that conjugated linoleic acid (CLA) has been attributed for its anti-obesity, anti-carcinogenic, anti-atherosclerotic, immune-modulatory and anti-angiogenic activities. Research studies gave strong evidence that the cis-9, trans-11 (c9, t11) isomer of CLA has been produced from free linoleic acid by the probiotic $B$. breve and $L$. plantarum strains [61]. Furthermore, the suppression of colitis has been visualized by the administration of probiotic mixture VSL\#3 in mice [62]. It was reported that this improvement has been manifested by the elevated concentration of c9, t11 CLA by activating peroxisome proliferator-activated receptor gamma (PPAR $\gamma$ ) in macrophages. Therefore, LC-PUFA may possibly have therapeutic potential for preventing/treating the neurophysiological conditions.

\subsection{Quorum Sensing Molecules}

The phenomenon of orchestrated communication and expression of genetic language by different signaling molecules within the bacterial community is defined as quorum sensing. The diversity of these signaling molecules among gram positive and gram negative bacteria confers different functionality in the respective systems [63]. Within the realm of their positive health implications, several bioactive peptides have been identified that have been deployed for beneficial impact on the host health. Recent research investigations reported that an auto-inducer (furanosyl borate diester, AI-2) molecule of E. coli Nissle 1917 was found to induce the anti-inflammatory cytokines in acute colitis in a mouse model [64]. The significant contribution of AI-2 signaling molecule of probiotic Lactobacillus species has been well established by reduction in the adherence potential of this microbial population to IECs when IuxS gene has been disrupted [65]. Similarly, the anti-cancer potential of a QS system related peptide (CHWPR) of $B$. animalis subsp. lactis BB-12 has been reported. This peptide enhances the expression of $c-m y c$, and IL-6 genes in somatic cells that plays important role in regulation of cancer and serves as an anti- and pro-inflammatory cytokine, respectively [66]. In addition to that, cyclic thiolactone autoinducing peptide (CVGIW) encoded by the lamBDCA operon of L. plantarum WCFS1 has been reported to regulate the adhesion capability of this strain with intestinal epithelial cells. Furthermore, the capability of competitive pathogen exclusion by L. acidophilus NCFM has been demonstrated by enhanced transcription of the IuxS gene after co-cultivation with Listeria monocytogenes cells [67]. Based on the above information, it can be concluded that the quorum sensing molecules significantly affect the functioning of probiotics and may act as potential metabiotic components however the detailed knowledge has been clearly required.

\subsubsection{AHR Ligands}

Aryl hydrocarbon receptor (AHR) is known as transcription factor induced by 
the ligand and is expressed by epithelial cells, immune cells and some tumor cells and plays significant role in the regulation of mucosal immune responses. Research studies gave surmounting evidence that an absence of AHR ligands leads to the perturbations in gut microbial system resulting in the enhanced immunopathology and colonic inflammation [30]. The postnatal proliferation of intestinal lymphoid follicles (ILF) and specific innate lymphoid cell (ILC) populations has also been mediated by the AHR activation which was required for alleviation of the infection caused by Citrobacter rodentium [68]. Currently, it has been realized that there is strong interplay between host-microbial mutualism for adequate signalling of AHR molecules. The diet and gut microbial composition plays regulatory role in the activation of AHR. Till date, it was reported that Lactobacilli spp., can metabolize dietary tryptophan and produce AHR ligands that can stimulate ILCs [69]. The activation of ILC leads to the production of IL-22 that in turns enhances the expression of AMPs required for the inhibition of opportunistic fungus Candida albicans [70]. Furthermore, it also protects from inflammation at mucosal interfaces but future research must be warranted for exploring their potential for the treatment of infectious and inflammatory disorders.

\subsubsection{Bioactive Peptides}

The great interest has been spurred on bioactive peptides present naturally in the food matrices that can be encrypted through the microbial proteolytic systems from their proteinaceous counterpart. A wide spectrum of remarkable functions has been credited to their account that includes antithrombotic, anti-hypertensive, immune-modulating, osteoprotective, anti-lipemic properties, antioxidants, opioid and opioid antagonists, angiotensin-converting enzyme inhibitors [71]. Recent research envisaged that these peptides also play significant role in protein folding, regulation of cell cycle and apoptosis. The enzymatic pool of human digestive system including chymotrypsin, pepsin, pancreatin, thermolysin and alcalase has been used to release the bioactive peptides from various proteins that can be absorbed by the gut and then reach peripheral organs [72]. Besides that, the proteolytic system of Lactic acid bacteria (LAB) significantly contributes the release of bioactive peptides either into the food matrix or in the gut. Bioactive peptides with various functionalities have been identified in several dairy-products such as cheese, fermented milk, milk protein hydrolysates and various meat products [73]. Their origin and various functionalities are summarized in Table 1 [74]-[79].

\subsubsection{Vitamins}

Vitamins are indispensible micronutrients required for healthy metabolism. The dieatray interventions are required for the vitamins as humans are not capable of synthesizing most vitamins. Probiotic bacteria (e.g., Lactococcus lactis, Lactobacillus gasseri, and Lactobacillus reuteri) and Bifidobacterium (e.g., B. adolescentis) Propionibacteria freudenreichii, and members of the gut microbiota [80] are able to synthesize vitamin $\mathrm{K}$ and water-soluble $\mathrm{B}$ vitamins such as folates, 
Table 1. The functionality of various bioactive peptides derived from probiotics.

\begin{tabular}{|c|c|c|c|}
\hline PRODUCT & FUNCTIONALITY & PEPTIDE SEQUENCE & REFERENCES \\
\hline $\begin{array}{l}\text { Meat (Proteolysis, } \\
\text { oxidation) }\end{array}$ & ACE-I activity & $\begin{array}{l}\text { APPPPAEVFEVHEEVH, } \\
\text { PPPAEVTEVHEEVH, } \\
\text { IPTTAAKASRNIA, LPLGC, } \\
\text { FAGGRGG, APPPPAEPP }\end{array}$ & {$[74][75][76]$} \\
\hline $\begin{array}{l}\text { Meat (Enzymatic } \\
\text { hydrolysis) }\end{array}$ & $\begin{array}{l}\text { ACE-I antioxidant, } \\
\text { antithrombotic, } \\
\text { antimicrobial \& } \\
\text { anticancerous }\end{array}$ & $\begin{array}{c}\text { KRQKYD, EKERERQ, KAPVA, } \\
\text { PTPVT, RPR, GLSDGEWQ, GFHI, } \\
\text { DFHING, FHG }\end{array}$ & {$[77][78]$} \\
\hline Meat (Cooking) & ACE-I activity & $\begin{array}{c}\text { SPLPPPE, EGPQGPPGPVG, } \\
\text { PGLIGARGBPGP }\end{array}$ & {$[75]$} \\
\hline Sour milk & $\begin{array}{l}\text { Reduction of blood } \\
\text { pressure }\end{array}$ & VPP, IPP & {$[44]$} \\
\hline $\begin{array}{l}\text { Fermented milk } \\
\text { (Calcium } \\
\text { enriched) }\end{array}$ & $\begin{array}{l}\text { Reduction of blood } \\
\text { pressure }\end{array}$ & VPP, IPP & [44] \\
\hline $\begin{array}{l}\text { Hydrolysed whey } \\
\text { protein isolate }\end{array}$ & $\begin{array}{l}\text { Reduction of blood } \\
\text { pressure }\end{array}$ & Whey peptides & [44] \\
\hline Whey protein & $\begin{array}{l}\text { Anticancerous, } \\
\text { antimicrobial }\end{array}$ & $\begin{array}{l}\text { AMKPWIQPKTKVIPYVRYLKPWIQPKT } \\
\text { KVIPYVRYL, LKKISQRYQKFALPQY, } \\
\text { FKCRRWQWRM, IKHQGLPQE, } \\
\text { VLNENLLR, SDIPNPIGSEN, SEK }\end{array}$ & {$[44]$} \\
\hline $\begin{array}{l}\text { Fermented } \\
\text { low-fat hard } \\
\text { cheese }\end{array}$ & $\begin{array}{l}\text { Reduction of blood } \\
\text { pressure }\end{array}$ & $\begin{array}{c}\text { MRLLILTCLVAVALARPKLPLRYPERLQ } \\
\text { NPSESSEPIPLESREEYMNGMNRQRNIL } \\
\text { REKQTDEIKDTRNESTQNCVVAE- } \\
\text { PEKMESSISSSSEEMSLSKCAEQFCRaL- } \\
\text { NEYNQLQLQAAHAQEQIRRMNENSH } \\
\text { VQVPFQQLNQLAAYPYAVWYYPQIM } \\
\text { QYVPFPPFSDISNPTAHENYEKNNVML } \\
\text { QW, RPKHPI }\end{array}$ & {$[44]$} \\
\hline
\end{tabular}

biotin, nicotinic acid, cobalamine, riboflavin, thiamine, pyridoxine and pantothenic acid in humans [81] [82]. Therefore, the magnificent property of probiotics for the production of vitamins has been envisaged as sustainable alternative for the bio-fortification as compared with chemically synthesized pseudovitamins.

\subsubsection{Miscellaneous}

The continuous cross talk between gut ecosystem and host cells has been stringently controlled by the mutual exchange of small molecular weight molecules that have beneficial health implications. Among the plethora of these molecules various other metabolites secreted by probiotic community are utilized for the well-being of the host cells. For example, lectins present in the surface of probiotic organisms are active regulators of metabolism, facilitate the adhesion process and induces various signaling pathways. Moreover, plasmogens, a glycerophospholipid present in cytoplasmic membrane of $B$. animalis subsp. lactis [83] has served the function of potential antioxidant and confers protective role in various neurodegenerative disorders like down syndrome [84] Alzheimer disease [85], experimental autoimmune encephalomyelitis [86] and Parkinson's 
disease [87]. Furthermore, research studies envisaged the beneficial functions of nucleotides of probiotic organisms that includes as some anti-aging molecules, memory improvement, enhancement of disease resistance, improvement of the growth rate. In addition to that, studies have also reported that small interfering RNAs has been utilized for inhibition of HIV, influenza infection and hepatitis [88]. In continuation with this, certain amino acid derivatives including selenocysteines and selenomethionines, have been reported to be synthesized in yeasts and Lactobacilli [89]. They have been found to play protective role against cancer, counteract oxidative stress and activate anabolic pathways of thyroid hormone biosynthesis and modulate immune system. Based on the above discussion, metabiotics possess remarkable credentials in terms of beneficial health aspects and act through varied mechanisms in the human body but more and more in-depth studies must be warranted for their validation and commercial scale utilization.

\section{Beneficial Implications of Metabiotics}

\subsection{Role of Metabiotics in Neuromodulation}

The myriad of microbial population residing in gut constitutes a complex neural network known as enteric nervous system. Their main function can be relayed to modulate the communication between the gut and the central nervous system in both gut-to-brain and a brain-to-gut direction that is nowadays recognized as "gut-brain axis". The marvellous coordination between the brain, gut and immune and endocrine system express complete neuro-homeostasis of an individual. This communication is mediated by the production of neuroactive and neuroendocrine molecules such as GABA, acetylcholine, serotonin, dopamine, histamine, noradrenaline and adrenaline by gut microbial communities. The various metabolites and their producing organism having diversified neuromodulatory effects are summarized in Table 2 [89]-[102]. The disruptions in the gut-brain axis have been associated with neurological disorders like depression, alterations in the cognitive ability, Alzheimer's, Parkinson's, Autism spectral disorders. Therefore, investigations on the various neuromodulatory molecules as metabiotic components released by the gut microbial species have been of immense interest nowadays. The effects of these molecules on the various neurological disorders are summarized below:

\subsubsection{Autism Spectrum Disorder}

Autism spectrum disorders (ASDs) are neurodevelopmental disorders characterized by dysfunctioning in communication skills and social interaction [103] [104]. Though various genetic and environmental factors play significant role in the development of ASD but perturbations in gastrointestinal (GI) integrity due to alteration in gut microbiota has been strongly linked to the development of ASD [105]. Research studies demonstrated the fact that reduction in the population of probiotics like Akkermansia muciniphila and Bifidobacterium spp. has been observed in the gut of ASD patients. Furthermore, similar social 
Table 2. Neuromodulatory activity of various metabiotics.

\begin{tabular}{ccc}
\hline METABOLITES & SOURCE & FUNCTION \\
\hline GABA & Lactobacillus, Bifidobacterium & $\begin{array}{c}\text { Inhibitory neurotransmitters, } \\
\text { prevents anxiety \& depression [82] }\end{array}$ \\
Serotonin & $\begin{array}{c}\text { Streptococcus, Escherichia, } \\
\text { enterococci, Enterococcus, } \\
\text { Lactococcus, Lactobacillus }\end{array}$ & $\begin{array}{c}\text { Neurotransmitter, control } \\
\text { emotion [83] [84] }\end{array}$ \\
Norepinephrine & Bacillus & $\begin{array}{c}\text { Neurotransmitters, central nervous } \\
\text { and endocrine regulation [83] [85] }\end{array}$ \\
Acetylcholine & Lactobacillus, Bacillus & Act on neurotransmitters, involved in \\
learning \& memory [86] [87]
\end{tabular}

deficit behaviours like ASD has also been observed in germ-free mice suggesting that the microbiota plays vital role in the development of social behaviour and the etiology of ASDs [106]. In addition to that, amelioration of some behavioural dysfunction has been observed by the administration of Bacteroides fragilis in early adolescence period in a mouse model of autism. Moreover, the increase in the synthesis of dopamine and its related catecholamines through induction of tyrosine hydroxylase by SCFA released by various probiotic species also modulate the symptoms of ASD. The more detailed investigations are required for understating the potential link between microbiota and autism.

\subsubsection{Anxiety and Depression}

The traumatic life events accompanied with chronic stress leads to the depression and anxiety like neurological disorders. Recent research studies highlighted the importance of probiotics for the alleviation of depression. It has been reported that the dysfunctioning of Gamma-aminobutyric acid (GABA) in the brain has been linked to anxiety and depression. Recently, it has been demonstrated that some strains of Lactobacilli and Bifidobacteria produce GABA from monosodium glutamate (MSG) and imparts considerable effect on the brain-gut axis [98]. Similarly, administration of L. rhamnosus JB-1 to mice resulted in diminished anxiety and depression-related behaviour due to the altered patterns of GABA receptors in the brain and reduction in stress-induced corticosterone 
[107]. In addition to that, similar antidepressant effect of GABA has been seen as compared with fluoxetine by the administration of black soybean milk enriched with GABA which is produced by L. brevis FPA3709 into the rats without the side effects of appetite loss and decreased weight [108]. Moreover, serotonin level also regulates the depression and mood. Some research studies indicated that probiotic bacteria can synthesize serotonin or induce its production by the host. Therefore, these metabiotic components described above could be suitable alternatives as non-conventional anti-depressants but still the careful futuristic studies are needed for their efficacy and dose in the humans.

\subsubsection{Cognition}

Cognition, one of the important physiological phenomenon that depicts the thought process for executing decisive ability and problem-solving function that is affected in serious neurological disorders like schizophrenia, depression, Alzheimer's disease, Parkinson's disease. Despite great advances has been seen for the enhanced understanding towards the cognitive process but still multitude symptoms of the cognitive deficit has been challenging due to less efficient treatment modalities. Currently, the role of microbiota in alleviating the cognition deficits has been greatly acknowledged [109]. It was hypothesized that the neuroactive metabolites produced by the probiotics and other gut microbial species enhance the cognitive process. It has been envisaged that there has been enhancement of memory after the treatment with probiotics in naive rodents and where memory deficits has been observed after the stress exposure and infection with Citrobacter rodentium in the same organism. Furthermore, histamine secreted by various probiotic species like Streptococcus, Enterococcus, Lactococcus, Lactobacillus, Pediococcus plays important roles in cognitive function. The alterations in histamine level in temporal cortex, hippocampus and hypothalamus in Alzheimer's disease leads to the degeneration of histaminergic neurons affecting the cognitive functions further confirms its potential role. Moreover, acetylcholine a well-known neurotransmitter synthesized in CNS but also produced by the strain of $L$. plantarum. It plays a critical role in cognitive function, particularly in memory and learning. Therefore, these molecules may be utilized as potential metabiotic components for enhancing the cognitive performance but detailed studies have been warranted in clinical and preclinical models.

\subsubsection{Alzheimer's Diseases}

Alzheimer's disease (AD) is currently recognized as the chronic neurodegenerative disorder not limited to the ageing population but also affects younger generation. There is interplay between the several genetic and environmental reasons that can be correlated with the pathogenesis of $\mathrm{AD}$ but the deposition of extracellular $\beta$ amyloid (A $\beta$ ) senile plaques (SP) and intracellular neurofibrallary tangles (NFT) has been recognized as the major factors for contributing the disease development [110] [111]. Recent research investigations emphasized the role of gut microbiome as the major environmental factor for affecting this dis- 
ease [110]. The research studies revealed that by the administration of L.johnsonii in host ileum leads to the delayed progression of this disease due to the secretion of anti-inflammatory cytokines. Moreover the SCFAs like butyrate and propionate secreted by L. rhamnosus, L. reuteri and Bacterioides fragilis modulate the cholinergic neuronal signalling and anti-inflammatory pathway of the vagus nerves of the brain suppressing the effect of AD. Furthermore, the role of suppression of the oxidative stress markers released by L. acidophilus and L.casei species also confirms their significant role in the reduction of AD [110]. Moreover, the prominent role of indole-3-propionic acid (IPA) as a treatment modality for $\mathrm{AD}$ has been recently come into limelight. It acts as a powerful antioxidant by protecting neurons and neuroblastoma cells against oxidative damage and produced by gut microbiome [112]. In addition to that ferulic acid released by some Lactobacillus species has been demonstrated their beneficial health effects by reduction in deposition of $\beta$ amyloid plaques, reversal of memory deficits, improves cognition and affecting the acetylcholine esterase activity. FA also plays important role in the restoration of antioxidant genes and expression of HSP 70 [113]. These all factors play important role in the etiology of AD and based on these research speculations the bioactive metabolites produced by gut microbial species plays a supporting role for the suppression of AD.

\subsubsection{Parkinson's Disease}

Parkinson's disease (PD) is a complex neurodegenerative disease manifested by motor impairments [114]. Though the disease is known to be idiopathic, perturbations in gastrointestinal function due to the accumulation of alpha-synuclein and subsequent mucosal inflammation have been implicated as major reason for the onset of this disease. The research studies thoroughly supported the fact that there is active involvement of enteric nervous system in pathological progression of this disease towards the central nervous system [115]. Currently, the research investigations related to use of probiotics and other gut microbiome in direct correlation with preventive or therapeutic modalities has been found to be very limited. Some studies have shown that butyrate an important SCFA as neuroactive molecules has been found to improve the reduction in the degeneration of dopaminergic neurons and pre-motor cognitive deficits that leads to prevention from early mortality. Furthermore, the anti-inflammatory and antioxidant property of ferulic acid leads to the inhibition of lipid and protein oxidation and down regulates the synthesis of pro-inflammatory cytokines. Some research studies also demonstrated that the administration of Lactobacillus casei shirota alleviates the symptoms of constipation severity from the patients suffering from PD [116]. Therefore, based on the above speculations it can be concluded that metabolites from probiotics may serve as a powerful tool to improve the GI dysfunction, bacterial translocation, protects from neuro-degeneration and alleviate neuro-inflammation that may leads to the suppression of Parkinson's disease. 


\subsection{Role of Metabiotics in Protecting Auto-Immunity}

Autoimmunity is defined as the phenomenon of recognizing the own body cells as an antigen through the production of auto-antibodies in certain tissues. The growing complications associated with auto-immune disorders are on the rise worldwide. These disorders include rheumatoid arthritis (RA), diabetes, systemic lupus erthrymatosus (SLE), autoimmune encephalomyelitis (EAE), Grave's disease and inflammatory bowel disease (IBD) [117] [118]. The various genetic and environmental reasons are associated with the serious health outcomes [119]. Recent research envisaged the considerable role of gut microbiome in the progression as well as prophylactic measures for abrogating these complex disorders. In fact, the altered gut microbiome represented themselves as diagnostic markers for these diseases. For example, studies reported that in the RA patients, the levels of opportunistic pathogens such as Enterobacterium and Staphylococcus were increased while reduced levels were observed for the strains such as Lactobacillus, Bifidobacterium, Bacteroides [120]. Similarly, reduced Firmicutes/Bacteriodetes ratio has been reported in the intestinal microenvironment of patients with SLE [121].

Furthermore, studies were performed and it was found that probiotics interventions affect the various anti-inflammatory and immune-modulatory pathways by which various proteins like mucin, HSP-70, anti-inflammatory mediators have been released that help in the alleviation of the auto-immune disorders [122]. Research investigations demonstrated that treatment L. paracasei DSM 13,434 and L. plantarum DSM 15312 [123] suppress the inflammation in the murine experimental autoimmune encephalomyelitis (EAE) model by accumulation of $\mathrm{T}_{\text {reg }}$ cells in the lymphoid organs. Similarly, reduced clinical symptoms of Grave's disease have been observed by down-regulation of inflammatory mediators through the generation of regulatory dendritic cells (rDCs) by the administration of IRT5 (combination of Streptococcus thermophilus, Lactobacillus reuteri, Bifidobacterium bifidum, Lactobacillus acidophilus and Lactobacillus casei probiotics). The regulatory dendritic cells upregulate the production of IL-10, arginase 1, TGF- $\beta$, and aldh1a2 that decreased the acetylcholine receptor (AChR)-reactive lymphocyte proliferation. Similar studies were reported for alleviation of IBD by the enhanced production of $\mathrm{T}_{\text {reg }}$ cells after the administration of Faecalibacterium prausnitzii and Bifidobacterium in the preclinical mice model [124]. Moreover, collagen-induced arthritis (CIA) has been suppressed by the oral administration of $L$. casei. This has been accomplished by the reduction in the pro-inflammatory molecules (I TNF-alpha, IFN-gamma, IL-2, IL-6, IL-12, IL-17 and Cox-2) by T cells [125]. A similar effect was observed in a study using Lactobacillus $G G$ strain in antigen-induced arthritis model of Lewis rats [126]. Based on the above discussion, various positive implications have been reported with different components of probiotic bacteria either as prophylactic or preventive measures in the preclinical auto-immune animal models. Therefore, futuristic studies can be correlated with human clinical trials for assessing their wider impact. 


\subsection{Role of Metabiotics in Metabolic Syndrome}

The global prevalence of metabolic syndrome (MS) due to the alterations in energy metabolism leads to the various life style diseases like diabetes, obesity, cardiovascular risk and stress. Theses metabolic alterations occur due to somewhat unexplained perturbations on carbohydrate, fat and protein metabolism that significantly affect cellular growth, differentiation and affect various neurological activities. The correlation between metabolic syndrome with nervous system that leads to the neurodegenerative diseases are depicted in Figure 7. The current scientific observation leads to the persuasive impact of gut microbiome on the various premises of energy metabolism. The alterations in gut microbiome lead to oxidative stress, hypercholesterolemia, metabolic endotoxemia, dyslipidemia. The current scientific interventions can be correlated with their beneficial significance for the amelioration of these metabolic disorders through reduction of oxidative stress, enhanced absorption of antioxidants, immunomodulation, modification of the intestinal microbiota, reduces inflammation and post prandial lipid concentrations. There are an increasing number of studies exploring the effects of various metabolites as metabiotic components from the probiotic strains in the prevention or treatment of metabolic and cardiovascular risk factors.

\subsubsection{Role in Diabetes and Obesity}

The past decade has experienced the global prevalence of an epidemic in the form of Type 2 diabetes mellitus and obesity due to over-nutrition and sedentary lifestyle [127]. The recent research highlighted the prominent role of SCFAs produced by Lactobacillus species in energy homeostasis and they serve as magnificent ligands for two orphan GPCRs receptors, GPR41 (known as FFAR3) and GPR43 (known as FFAR2) [128]. Acetate and propionate binds to the FFAR2 whereas FFAR3 has been more often activated by propionate and butyrate [129]. The activation of these ligands leads to the enhancement in the level of GLP-1 and peptide YY (PYY) that improves the insulin secretion and resistance [130]. These peptides also help in the reduction of plasma glucose concentration, endoteximia and preserving pancreatic $\beta$-cell function. Moreover, the SCFAs produced with $L$. paracasei subsp. paracasei NTU 101 changes the intestinal $\mathrm{pH}$ that inturn enhanced the level of Bifidobacterium spp. leads to the reduction in type 2 diabetes mellitus by up-regulating the gene expression profile of the intestinal tight junction markers and gut integrity. Furthermore, the administration of probiotic $B$. animalis subsp. lactis 420 metabolites reduces the inflammation and insulin resistance by ameliorating the dysbiosis and preserving the adherence of intestinal mucosa [131]. In addition to that, by the activation of GPR43, acetate inhibits fat accumulation in adipocytes and reduces appetite through a central hypothalamic mechanism.

More recently, it was shown that the administration of Bifidobacterium animalis ssp. lactis GCL2505 (BlaG), reduced visceral fat accumulation and improved glucose tolerance levels by theory secreted metabolites like acetate and 


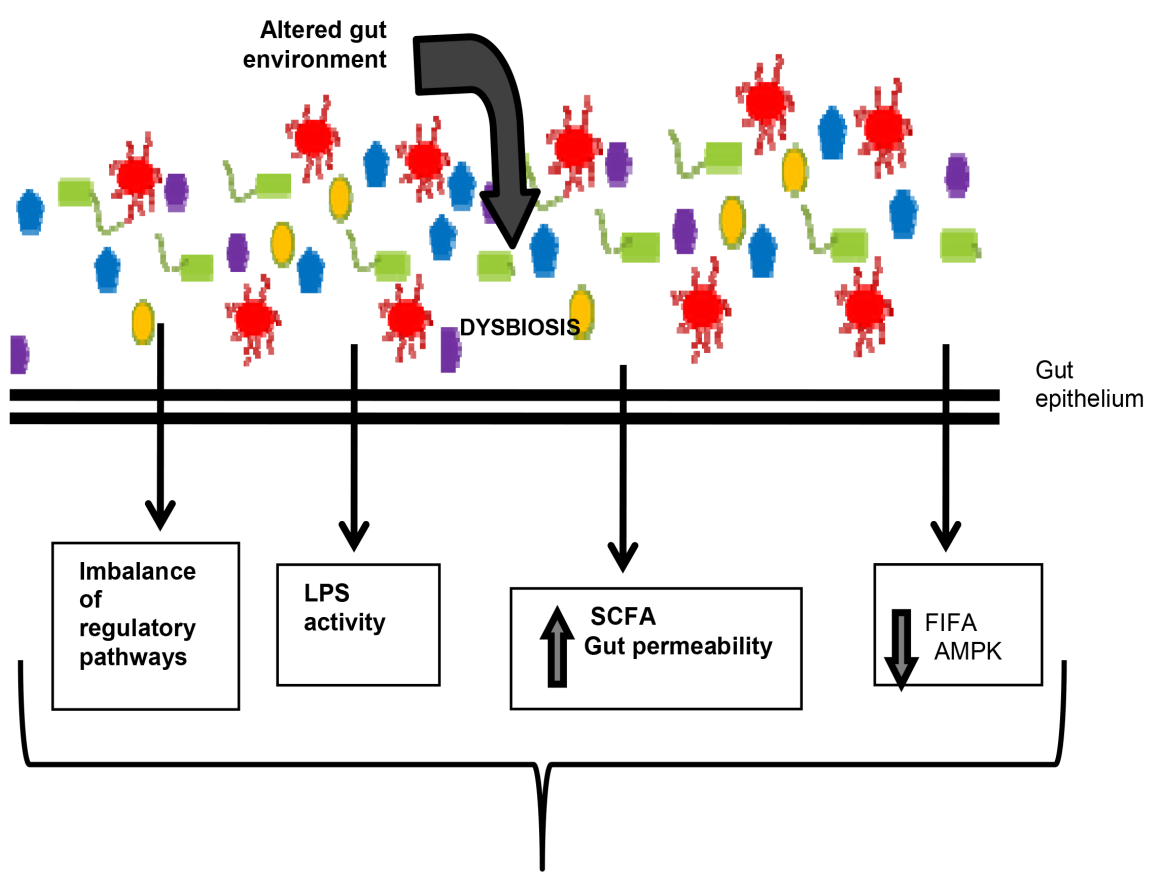

Inflammatory

cytokines production

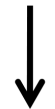

Metabolic syndrome

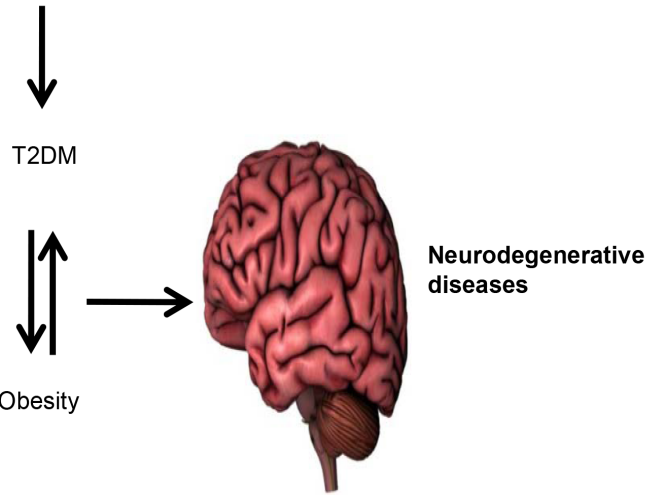

Figure 7. Role of dysbiosis in metabolic syndrome and its correlation with neurodegeneration.

glucagon-like peptide-1 that confirms their anti-MS effect on the mice model [132]. Additional research has indicated that SCFAs are actively involved in the liver metabolism that significantly impact on the obesity. Research studies gave strong evidence that there is significant deviation in the metabolism of liver in gnotobioic mice and colonized mice due to the increased influx of SCFAs and the increased production of the triglyceride transporters into the liver of colonized mice [133]. This enhancement is associated with the reduced expression of fasting-induced adipose factors or angiopoietin-like 4 (ANGPTL4). ANGPTL4 is 
also a downstream target gene of peroxisome proliferator activated receptors (PPARs), the agonists of which are widely utilized for the treatment of T2DM and CVD and constitutes the master regulator of adipogenesis [134]. Apart from that, SCFAs also control the proteins like endocannabinoid system and the tight junction protein zona occludin-1 which are involved in the control of inflammation, nutrient oxidation, and storage [135]. Furthermore, an immuno-modulatory activity has been done by butyrate by inhibiting the secretion of pro-inflammatory cytokines IL-12 and TNF- $\alpha$ and enhancement in the release of the anti-inflammatory cytokine IL-10 by monocytes [136] and thereby provided immunity to the development of T1DM in diabetes prone rats. The research studies also highlighted that butyrate and propionate can also play protective role against diet-induced obesity. In continuation with this, metabolites of probiotic also alleviate the severity of T2DM and NAFLD by reducing the levels of IL-6, IL-8, IL-1, IF- $\gamma$ and TNF- $\alpha$ by enhanced expression of antioxidant enzymes like glutathione peroxidase and erythrocyte superoxide dismutase.

\subsubsection{Role in Cardiovascular Disease}

The metabolic syndrome also constitutes the various risk factors for the cardiovascular disease that primarily stems from deposition of high levels of LDL-cholesterol and dyslipidaemia. Recently, the positive implications of gut derived metabolites have been come into existence with adequate evidences. The complete elucidation of mechanism of their action has yet to unravel but the enzymatic deconjugation of bile acids by bile-salt hydrolase (BSH) has been proposed as an important molecular mechanism in the reduction of cholesterol [137]. Researchers found that BSH activity was found in many of probiotic strains that reduce the serum cholesterol either by increasing the demand for cholesterol for de novo synthesis of bile acids to replace those lost in faeces or by absorption of cholesterol through the intestinal lumen through the reduction in cholesterol solubility. The various research studies confirm the hypercholesterolaemic effect of BSH produced by L. plantarum $\mathrm{PH} 04, B$. Bb-12 or B. longum $B b-46, L$. acidophilus $L 1$ and $L$. reuteri [138]. Apart from the BSH activity, recent research suggest that exo-polysaccharides released from some Lactobacillus species has also shown cholesterol removing ability in mice model though their clinical validation has been under progress.

Furthermore, a novel protein, p 75 has been isolated and purified from $L$. rhamnosus GG that leads to reduced ischemic injury, improved cardiac function and heart tissue infarction [139]. This was mediated through the enhanced expression of HSPs with $\mathrm{p} 75$ pretreatment. Similar reduced myocardial infarction has been observed with the oral consumption of L. plantarum 299 v. The attenuated ischemic injury was mediated by reduction in the concentration of leptin hormone in serum [140]. As hypertension is considered as the major risk factors for the development of CVD therefore positive implications of bioactive peptides of gut microbiome has been assessed for reduction in hypertension. Research studies reported that certain strains of Lactobacillus and Bifidobacterium strains 
alleviate the symptoms of hypertension by producing bioactive peptides with angiotensin converting enzyme ACE-inhibitory activity through the proteolysis and fermentation of milk proteins [141]. Similar studies have been reported in which the systolic and diastolic blood pressure in pre-hypertensive and hypertensive patients has been reduced by the consumption of probiotic fermented milk. Moreover, the ACE inhibitory activity was increased by the enhanced growth of Lactobacillus and Bifidobacterium strains has been reported by the inclusion of prebiotic components (inulin, pectin, fructo-oligosaccharides and mannitol) that positively correlated their anti-hypertensive activity.

\subsection{Role of Metabiotics in Oral Health}

The growing utilization of probiotics in maintaining the oral health is of current thrust area of research [142]. These microbial populations are well adapted for the oral environmental conditions that lead to their effective colonization and growth in mouth that inhibits the oral pathogens. Besides that, the immersive applications have been envisaged in dentistry as oral replacement therapy where the capacity of probiotics for the biofilm formation has been utilized for the competitive exclusion of cariogenic and periodontal pathogens that leads to the prevention of caries and gingivitis. The studies have been continuously emerging for identifying their role for the improvement of oral health. Some research studies reported that the bacteriocins produced by the Streptococcus salivarius has been utilized for the reduction of anaerobic bacteria Porphyromonas gingivitis, Treponema denticola and Treponema forsythia associated with halitosis (malodor) [143]. Moreover, the anti-mycotics substances produced by Lactococcus cremoris, Lactococcus lactis spp. have been reported to alleviate the infection in voice prosthetic biofilms. More recently, the low $\mathrm{pH}$ milieu due to the SCFAs produced by $L$. rhammnosus $G G$ has been reported to reduce the prevalence of oral candidosis. In addition to that, anti-bacterial substances produced by $L$. gasseri and $L$. fermentum, in the oral cavity have been reported to inhibit chronic periodontitis [144]. A similar study was reported by using L. salivarius WB21 tablets to reduce the plaque index and periodontal pocket depth in individuals at high risk of PD [145]. Furthermore, research studies strongly supported the fact that the perturbations in the oral microbiome leads to higher risk of CVD therefore. Their cardio-protective role has also been realized by the conversion of dietary-derived inorganic nitrate $\left(\mathrm{NO}_{3}^{-}\right)$to nitrite $\left(\mathrm{NO}_{2}^{-}\right)$by the oral bacteria. This is mediated by some Lactobacillus species and Actinomyces odontolyticus. It was shown that production of nitric oxide (NO) through the "nitrate-nitrite-nitric oxide" pathway has been shown to increase vasodilatation, improve vascular endothelial function and decrease blood pressure that affect the occurrence of CVD in the individuals. Therefore, based on this discussion the oral microbiome has become an emerging subject in the field of oral health and further more clinical evaluations are required for the complete elucidation of their beneficial impact. 


\subsection{Role of Metabiotics in Competitive Pathogen Exclusion}

In the past decade, the dramatic rise in the incidence and severity of pathogenic infections raised serious concerns at global level due to the emergence of hyper-virulent strains. The various therapeutic modalities have been developed to eradicate or prevent infections by inclusion of antibiotics or by enhancing intestinal barrier function and modulating the host immune system. The intestinal microbial consortium plays pivotal role in prevention of colonization of pathogenic bacteria so called "barrier or competitive-exclusion effect" through the production of anti-microbial compounds, peptides, and proteins by inhibiting the toxins produced by the pathogens [146]. The plethora of literature revealed that Lactobacilli and Bifidobacteria have been profusely utilized for the inhibition of a broad range of pathogens, including Salmonella, Helicobacter pylori, Campylobacter jejuni, E. coli, Rota virus, Listeria monocytogenes etc. [147]. Research studies reported that an efficient treatment of $C$. difficile associated diarrhoea and colitis was done by administration of probiotic yeast Saccharomyces boulardii which encodes a protease that digest toxin A and B molecules and its membrane receptor of this pathogen and also inhibit in vitro cell adherence [148]. Furthermore, the alleviation of $S$. aureus and $C$. difficile has been reported by the action of bacteriocin (clausin) produced by the probiotic B. clausii strain O/C. Similar studies was reported for the antimicrobial activity in mouse model against $C$. difficile infection by the production of thuricin $\mathrm{CD}$ from $B$. thuringiensis [149]. In addition to that $C$. difficile infection was ameliorated by the actin of Lacticin 3147, a broad-spectrum bacteriocin produced by Lactococcus lactis. Moreover, cell free supernatant of $L$. acidophilus GP1B demonstrated anti-microbial activity by inhibiting the autoinducer-2 (AI-2) quorum sensing molecule of pathogens like E. coli O157:H7, C. difficile and C. perfringens and down regulate the virulence coding toxin genes. Furthermore, the surface proteins (MUC3) identified from co-culture of L. plantarum 299v and L. rhamnosus $G G$ inhibited the adhesion of enteropathogenic E. coli strain E2348/69 in HT20-MTX cells [150]. Similarly, Mub mucus-binding protein of L. reuteri 1063 has also found to possess putative adhesive function on intestinal epithelial cells and inhibit the binding of pathogens [151]. Furthermore, research studies also reported that adhesive protein of L. rhamnosus, was found to inhibit the internalization of EHEC (enterohemorrhagic E. coli) in a human intestinal cell line [152]. In addition to that, exo-polysaccharides and lipoteichoic acid also facilitates the adhesion of probiotic microorganisms to intestinal mucus/epithelial surfaces for the competitive exclusion of pathogens. More recently, the improvement of the symptoms of $H$. pylori infections has been demonstrated by the administration of cell free supernatant of Lactobacillus $G G$ and $S$. boulardii in the infected patients [153]. Therefore, based on the above-mentioned reports, the metabiotic components have significant capability of inhibiting the pathogenic bacteria by various mechanisms and render the well-being of host cells. 


\subsection{Role of Metabiotics in Cancer}

In recent decades, cancers are recognized as most intractable and prevalent diseases worldwide. The biological complexity associated with cancers limits the development of various diagnostic and treatment modalities. The overwhelming studies related to the role of gut microbiome have been proven to modulate-ameliorate the prevention and treatment of various cancers [154]. Currently, the scientific studies have been enriched with positive implications of different metabolic signatures produced by beneficial microbial population that plays vital role for the prevention of cancer by affecting various processes like apoptosis, anti-inflammation, immunomodulation and polyamine metabolism, production of anti-tumorigenic compounds and degradation of carcinogens.

Among the various metabolites SCFAs plays pivotal role for the prevention of cancers [155] [156]. They are able to silence the tumor suppressor genes by the inhibition of HDAC that is responsible for relaxing the structure of chromatin and creating opportunity for the binding of various transcription factors which in-turn activate the various target anti-cancerous genes as well as modulates the immune response by generating T regulatory cells [157] [158]. Recently, the anti-cancerous effects of SCFAs have also been highlighted in gastric cancer that is caused by infection with $H$. pylori that harbour oncogenic protein called as cytotoxin associated gene pathogenicity island (Cag PAI) [159]. This protein is transported across the host cell membrane and induces dephosphorylation of histone $\mathrm{H} 3 \mathrm{~S} 10, \mathrm{H} 3$ threonine 3, and de-acetylation of $\mathrm{H} 3 \mathrm{~K} 23$ in gastric epithelial cells and leads to malignant conversion of the normal gastric cells [160]. The epigenetic regulation of SCFAs by suppressing excessive responses of HDAC- or HAT plays a significant role in altering these histone modifications. More recently, bacteriocins derived from Enteroccus faecium, B. subtilis and Bifidobacterium has been found to alleviate gastric cancer by inhibiting $H$. pylori growth. Moreover, butyrate, the thoroughly investigated SCFA, has ability to convert procaspase 3 to active caspase 3 leads to induction of apoptosis in colon cancer cells [161]. In addition to that, research studies also reported that butyrate also induce cell cycle arrest as well as terminal differentiation by down regulation of cell cycle regulator CB1 mRNA expression and induction of cell cycle inhibitor p21 and the anti-apoptotic protein Bcl-2 [162] [163] in HT-29 cells. Furthermore, butyrate also has protective role by modulating canonical Wnt signaling pathway constitutively activated in colorectal cancers [164]. In addition to that, SCFAs produced by probiotic $P$. freudenreichii creates an acidic extracellular $\mathrm{pH}$ that is responsible for shifting of cancer cell state from apoptosis to necrosis [165]. Moreover, CFS of $B$. adolescentis SPM0212 has been found to demonstrate anti-colon cancer effect than whole cells or heat killed cells.

Similarly other SCFAs, propionate and acetate have also been reported to mediate anti-cancerous effects in colon by the condensation of nuclear chromatin. The generation of ROS and processing of caspase- 3 by altering the trans-membrane potential of mitochondrial membrane leads to the apoptotic 
pathways in colon cancer [166] [167] [168]. Furthermore, the protective role of SCFAs has been found in liver cancer by ameliorating the inflammation by binding with $G$ protein-coupled receptor 43 (GPCR43). The experimental studies conducted on GPR43-deficient (Gpr43-/-) mice confirmed that there has been increased inflammatory responses observed by the exacerbated recruitment of immune cells by the production of inflammatory mediators by Gpr43-/- cells [169]. Similarly, SCFAs produced by $P$. freudenreichii has also shown their anti-cancer effect on human colon and gastric cancer cell lines. In addition to that different cell free supernatants of $L$. casei 01 (heat treated cells, crude cell wall, intra cellular extracts and exo-polysaccharides) have been used for assessment of their anti-proliferative activity on 4-nitroquinoline $\mathrm{N}$-oxide (4-NQO) induced genotoxicity and colon cancer cell line (HT-29). The research findings stated that, among different modalities EPS induced higher anti-proliferative activity against HT-29 cancer cell lines [170]. Similarly, the cell free supernatant of $L$. acidophilus $36 \mathrm{YL}$ exhibited the potent cytotoxic effect against human cervical cancer cell lines (HeLa) and colorectal cancer cell lines (HT-29).

As cancer and oxidative stress are complementary to each other therefore the anti-oxidant effects of metabolites secreted by gut microbiome is well corelated with their anti-neoplastic activity. Recently, research studies demonstrated that exopolysaccharides (EPS) from $L$. plantarum C88 had an antioxidant effect which may involve scavenging of reactive oxygen species, enhanced regulation of enzymatic and non-enzymatic antioxidant activities and reduced lipid peroxidation. The cell free supernatant of $L$. salivarious REN inhibited the oxidative DNA damage in 4-nitroquinoline 1-oxide (4-NOO) induced oral cancer in mouse model. Similarly, exopolysaccharides from $L$. acidophilus (LA1) demonstrated their anti-tumour activity in vivo against Ehrlich ascites carcinoma (EAC) cells by suppression of malondialdehyde and nitric oxide in serum levels. Furthermore, EPSs of $L$. gasseri strains also showed their capability to inhibit cervical cancer cell (HeLa) growth and modulate immune response.

In continuation of this, the innate immune response was enhanced by the administration of various probiotc metabolic signatures. The studies revealed that both peptidoglycan (PGN) and lipoteichoic acid have been demonstrated to activate macrophages in a CD14-dependent manner. Lipoteichoic acid from Bifidobacteria and Streptococci also recognizes TLR-2, TLR-6 and triggers the signalling cascade for the production of cytokines that further leads to the anti-tumor activity. Similarly, (LTA) of L. acidophillus stimulates DCs to fabricate anti-inflammatory and regulatory cytokines in the form of IL-10 and IL-12, respectively. Furthermore, the anti-carcinogenic effects have been demonstrated by the inactivation of heterocyclic amines through the production of SCFAs. The production of SCFAs like formic, acetic, propionic, butyric and lactic acids creates the "Iuminal steady state" that is suggested to ameliorate the mutagenic potential of phenolic compounds, amines, ammonia, $N$-nitroso compounds and indoles derived from protein metabolism. 
Recent research studies revealed that besides SCFAs, medium chain fatty acids such as capric, caprylic, and caproic acids have also been reported to be cytotoxic against colon cancer cell lines [171]. The thoroughly investigated long chain fatty acid, conjugated linolein acid found in commercial preparation VSL\#3 have been found to possess anti-cancerous effects by inducing apoptosis, COX-2 inhibitor and activator of peroxisome proliferator-activated receptor gamma (PPAR g) in colon cancer and have also been able to mitigate intestinal tumorigenesis in Apc/C mice [172] [173] [174]. The CFS of E. lactis IW5 AND B. polyfermenticus (BPCM) have also demonstrated its anti-cancerous effect by inducing apoptosis in Caco-2 and HT-29 cancer cell lines. In addition to that the studies performed on porcine intestinal epithelial IPEC-1 cells infected with enterotoxigenic E. coli (ETEC)-concluded that the metabolites of $S$. cerevisiae CNCM I-3856 has the ability of preventing the cancer by alteration in the production of pro-inflammatory transcripts IL-6, IL-8, CCL20, CXCL2, and CXCL10 by down regulating ERK1/2 and p38 MAPK phosphorylation genes and up-regulating in the expression of peroxisome proliferator-activated receptor-c (PPAR-c) genes as an anti-inflammatory receptor [175]. In continuum of this, the progression of endometrial cancer stem-like cells has also been inhibited by sodium butyrate for the prevention of ovarian cancer [176].

Therefore, metabiotics may be utilized as promising approach for combating various cancers due to their remarkable ability to perform major functions such as regulation in cell differentiation, induction of apoptosis, cell cycle arrest as well as epigenetic regulation.

\section{Current Challenges}

The stupendous stride has been visualized in the prolific utilization of probiotics in maintaining the homeostasis of the host cell. In spite of the leveraged research imbibed by the scientific community for the beneficial implications of these microbial fraternity still lots of challenges has been envisaged to overcome for their commercial utilization. Till date, the beneficial credentials have been primarily assessed for the probiotic bacteria, the contribution of various virus, arachea bacteria, fungi have been lagging behind. The understanding of the synergistic or antagonistic effects of the host metabolites with metabiotics are priority area of the studies. It's very challenging to assess the functioning of these metabiotics in their preferred environmental niche in vivo rather than invitro conditions in terms of their intrinsic properties and pharmacokinetics. Moreover, the research studies should be strengthened by evaluating the clinical impact of metabioitcs on healthy as well as diseased individuals by the intervention of nutrigenomics approaches. Therefore, double-blind placebo-controlled human clinical trials for elucidating their beneficial effects must be needed for commercial utilization. Thus, the futuristic research approach related to metabiotics certainly underpins the progressive drives towards the understanding of molecular communication in the human gut. 


\section{Recent Progress and Future Directions}

The past decade has been seen tremendous breath-taking advances in understanding the role of microbial communities and their interactions with a host in relation to diet and lifestyle changes in the healthy as well as diseased state of an individual. The limitation of probiotics that has been overcome by the development of metabiotics has been seen prolific growth for the commercial production. The massive development has been seen in Russia but involvement of various industries across the globe developed different commercial metabiotics that are summarized in Table 3 [177] [178] [179] [180]. The technological advances led by "omic" technologies like transcriptomics, metabolomics and proteomics as well as culture-independent techniques has provided important insights for unravelling the more potential residing strain for the production of metabiotics. The genome analysis and its subsequent functional characterization of probiotics nowadays designated as pro-biogenomics have provided exciting novel opportunities for the identification of metabiotic components that is responsible for influencing the physiology and immune function of their respective host. The advent of bioinformatics tools and system biology approaches are being continuously utilized for understanding the detailed mechanism of bioactive compounds and their correlation with gut microbiota. The more recent technological endeavours of high-throughput sequencing from metagenomic and meta-transcriptomic sequencing (from cDNA libraries) reveals the functional relationship of probiotics and gut microbiome with respect to the host. The detailed understanding of initiation of molecular dialogue of surface associated proteomes has been intensively investigated with recently developed non-invasive tools like metaproteomics techniques.

Furthermore, the utilization of fluorescence in situ hybridization (FISH) was combined with single-cell imaging and metabolic oligosaccharide engineering (MOE) and bio-orthogonal click chemistry (BCC) with whole-body imaging has been in current use for tracking the microbial populations in invivo conditions. Therefore, these approaches certainly promise for expanding the knowledge towards metabiotics on host physiology, providing opportunities for developing the therapeutic approaches. There should be proper guidelines by separate regulatory Acts of National and International Agencies for the utilization of these molecules as drugs. Thus, by thorough understanding and production of metabiotics, a vision of personalized healthcare revolution is certainly on horizon.

\section{Conclusion}

The paradigmatic discovery of metabiotics leads to the progressive drive towards research and progression in this field. They have been found to possess magnificent capability of immunomodulation, pathogen exclusion and maintenance of gastro-intestinal integrity that attributed to their epigenetic effects at molecular level and served as potential molecules for abrogating various diseases. Though, the comprehensive understanding has been continuously thrived with recent 
Table 3. Commercialized metabiotics and their functions.

\begin{tabular}{|c|c|c|}
\hline PRODUCT & COMPOSITION & FUNCTIONALITY \\
\hline Hylak Forte & $\begin{array}{c}\text { E. coli DSM 4087, } S \text {. faecalis DSM 4086, } L \text {. } \\
\text { acidophilus } \text { DSM } 4149, \text { L. helveticus DSM } \\
\text { 4183; SCFA, lactic acid \& some } \\
\text { unidentified metabolites }\end{array}$ & $\begin{array}{l}\text { Eubiosis, acid-alkaline balance, } \\
\text { water-salt metabolism, Vitamin B \& K } \\
\text { balance, provide energy to intestinal } \\
\text { epithelia \& local immune cells }\end{array}$ \\
\hline Zakofalk & Inulin \& butyric acid & $\begin{array}{c}\text { Treatment of active inflammatory } \\
\text { intestinal diseases }\end{array}$ \\
\hline Bactistatin & B. subtilis, Vitamin $\mathrm{E}$ & $\begin{array}{l}\text { Immune defense, selective adsorption } \\
\text { and removal of toxins \& allergens, } \\
\text { ameliorates GI performance }\end{array}$ \\
\hline Aktoflor C & Lactic acid, lysine, succinic acid & $\begin{array}{c}\text { Reduction of intestinal disease } \\
\text { symptoms, avert antibiotics side effect }\end{array}$ \\
\hline Acilact & $\begin{array}{l}\text { Lactobacillus, fructo-oligosaccharide, } \\
\text { lactoferrin }\end{array}$ & $\begin{array}{l}\text { Reduce cholesterol level, therapy of } \\
\text { bacterial vaginosis }\end{array}$ \\
\hline Nagipol & $\begin{array}{l}\text { Yeast autolysate beer containing proteins, } \\
\text { amino acids \& vitamin B (B1-B6) }\end{array}$ & $\begin{array}{l}\text { Alleviates physical activity, lessen } \\
\text { resistant towards cold, anaemia \& } \\
\text { infectious disease of GI tract \& hepatitis }\end{array}$ \\
\hline Lacteol Forte & Heat killed $L$. fermentum \& L. delbruekii & $\begin{array}{l}\text { Treatment of HIV \& immunodeficiency } \\
\text { in infants \& patients }\end{array}$ \\
\hline
\end{tabular}

technological interventions but still we are very far from proving their clinically efficacy towards various disorders. Therefore, it is conceivable to envision that within the next decade the detailed understanding of these molecules will be unravelled that can facilitate the therapeutic and preventive avenues.

\section{Acknowledgements}

The authors wish gratitude towards Gautam Buddha University for providing necessary facilities for preparing the manuscript. All authors declare that they have no conflict of interest.

\section{References}

[1] Hopper, L.V. and Gordon, J.I. (2001) Commensal Host-Bacterial Relationships in the Gut. Science, 292, 1115-1118. https://doi.org/10.1126/science.1058709

[2] Sommer, F. and Backhed, F. (2013) The Gut Microbiota-Masters of Host Development and Physiology. Nature Reviews Microbiology, 11, 227-238. https://doi.org/10.1038/nrmicro2974

[3] Costello, E.K., Lauber, C.L., Hamady, M., Fierer, N., Gordon, J.I. and Knight, R. (2009) Bacterial Community Variation in Human Body Habitats across Space and Time. Science, 326, 1694-1697. https://doi.org/10.1126/science.1177486

[4] Bik, E.M., Long, C.D., Armitage, G.C., Loomer, P., Emerson, J., Mongodin, E.F., Nelson, K.E., Gill, S.R., Fraser-Liggett, C.M. and Relman, D.A. (2010) Bacterial Diversity in the Oral Cavity of 10 Healthy Individuals. ISME Journal, 4, 962-974. https://doi.org/10.1038/ismej.2010.30

[5] Kim, T.K., Thomas, S.M., Ho, M., Sharma, S., Reich, C.I., Frank, J.A., Yeater, K.M., Biggs, D.R., Nakamura, N., Stumpf, R., et al. (2009) Heterogeneity of Vaginal Microbial Communities within Individuals. Journal of Clinical Microbiology, 47, 1181-1189. https://doi.org/10.1128/JCM.00854-08 
[6] Pel, Z., Bini, E.J., Yang, L., Zhou, M., Francois, F. and Blaser, M.J. (2004) Bacterial Biota in the Human Distal Esophagus. Proceedings of the National Academy of Sciences of the United States of America, 101, 4250-4255. https://doi.org/10.1073/pnas.0306398101

[7] Price, L.B., Liu, C.M., Johnson, K.E., Aziz M., Lau, M.K., Bowers, J., Ravel, J., Keim, P.S., Serwadda, D., Wawer, M.J. and Gray, R.H. (2010) The Effects of Circumcision on the Penis Microbiome. PLoS ONE, 5, e8422. https://doi.org/10.1371/journal.pone.0008422

[8] Leebeer, S., Vanderleyden, J. and De Keersmaecker, S.C. (2008) Genes and Molecules of Lactobacilli Supporting Probiotic Action. Microbiology and Molecular Biology Reviews, 72, 728-764. https://doi.org/10.1128/MMBR.00017-08

[9] Singhal, B., Mukherjee, A. and Srivastav, S. (2016) Role of Probiotics in Pancreatic Cancer Prevention: The Prospects and Challenges. Advances in Bioscience and Biotechnology, 7, 468-500. https://doi.org/10.4236/abb.2016.711045

[10] Shenderov, B.A. (2013) Metabiotics: Novel Idea or Natural Development of Probiotic Conception. Microbial Ecology in Health and Disease, 24, 20399. https://doi.org/10.3402/mehd.v24i0.20399

[11] Shenderov, B.A. (2011) Probiotic (Symbiotic) Bacterial Languages. Anaerobe, 17, 490-495. https://doi.org/10.1016/j.anaerobe.2011.05.009

[12] Sonnenbur, J.L. and Fischbach, M.A. (2011) Community Health Care: Therapeutic Opportunities in the Human Microbiome. Science Translational Medicine, 3, 12.

[13] Neish, A.S. (2009) Microbes in Gastrointestinal Health and Disease. Gastroeneterology, 136, 65-80. https://doi.org/10.1053/j.gastro.2008.10.080

[14] Indriyani, A., Juffrie, M. and Setyati, A. (2012) Effects of Live versus Heat-Killed Probiotics on Acute Diarrhea in Young Children. Paediatr Indones, 52, 249-254. https://doi.org/10.14238/pi52.5.2012.249-54

[15] Caselli, M., Vaira, G., Girolamo, C., Papini, F., Holton, J. and Vaira, D. (2011) Structural Bacterial Molecules as Potential Candidates for an Evolution of the Classical Concept of Probiotics. Advances in Nutrition, 2, 372-376. https://doi.org/10.3945/an.111.000604

[16] Shenderov, B.A. and Gabrichevsky, G.N. (2017) Metabiotics: Overview of Progress, Opportunities and Challenges. Journal of Microbial \& Biochemical Technology, 9 , 11-21.

[17] Paul, B., Barnes, S., Demark-Wahnefried, W., Morrow, C., Salvador, C., Skibola, C. and Tollefsbol, T.O. (2015) Influences of Diet and the Gut Microbiome on Epigenetic Modulation in Cancer and Other Disease. Clinical Epigenetics, 7, 1-11.

[18] Shenderov, B.A. (2012) Gut Indigeneous Microbiota and Epigenetics. Microbial Ecology in Health and Disease, 23, 17195. https://doi.org/10.3402/mehd.v23i0.17195

[19] Sheflin, A.M., Whitney, A.K. and Weir, T.L. (2014) Cancer-Promoting Effects of Microbial Dysbiosis. Current Oncology Reports, 16, 406. https://doi.org/10.1007/s11912-014-0406-0

[20] Roberfroid, M., Gibson, G.R., Hoyles, L., McCartney A.L., Rastall, R., Rowland, I., Wolvers, D., Watzi, B., Szajewska, H., Stahl, B., et al. (2010) Prebiotic Concept and Health. British Journal of Nutrition, 2, S1-63. https://doi.org/10.1017/S0007114510003363

[21] Tomar, S.K., Anand, S., Sharma, P., Sangwan, V. and Mandal, S. (2015) Role of Probiotics, Prebiotics, Synbiotics and Postbiotics in Inhibition of Pathogens. Formatex, 717-732. 
[22] Besten, G.D., Eunen, K.V., Groen, A.K., Venema, K., Reijngoud, D.J. and Bakker, B.M. (2013) The Role of Short Chain Fatty Acids in the Interplay between Diet, Gut Microbiota, and Host Energy Metabolism. The Journal of Lipid Research, 54, 2325-2340. https://doi.org/10.1194/jlr.R036012

[23] Morrison, D.J. and Preston, T. (2015) Formation of Short Chain Fatty Acids by the Gut Microbiota and Their Impact on Human Metabolism. Gut Microbes, 7, 189-200.

[24] Kau, A.L., Ahern, P.P., Griffin, N.W., Goodman, A.L. and Gordon, J.I. (2012) Human Nutrition, the Gut Microbiome, and Immune System: Envisioning the Future. Nature, 474, 327-336. https://doi.org/10.1038/nature10213

[25] Fratta, E., Montico, B., Rizzo, A., Colizzi, F., Sigalotti, L. and Dolcetti, R. (2016) Epimutational Profile of Hematologic Malignancies as Attractive Target for New Epigenetic Therapies. Oncotarget, 7, 57327-57350.

https://doi.org/10.18632/oncotarget.10033

[26] Zitvogel, L. and Daillere, R., Roberti, M.P., Routy, B. and Kroemer, G. (2017) Anticancer Effects of the Microbiome and Its Products. Nature Reviews Microbiology, 15, 465-478. https://doi.org/10.1038/nrmicro.2017.44

[27] Barz, M.L., Anhe, F.F., Varin, T.V., Desjardins, Y., Levy, E., Roy, D., Urdaci, M.C. and Marette, A. (2015) Probiotics as Complementary Treatment for Metabolic Disorder. Diabetes and Metabolism Journal, 39, 291-303. https://doi.org/10.4093/dmj.2015.39.4.291

[28] Park, M.H. and Igarashi, K. (2013) Polymines and Their Metabolites as Diagnostic Markers of Human Diseases. Biomolecules \& Therapeutics, 21, 1-9. https://doi.org/10.4062/biomolther.2012.097

[29] Rhee, H.J., Kim, E.J. and Lee, J.K. (2007) Physiochemical Polyamines: Simple Primordial Stress Molecules. Journal of Cellular and Molecular Medicine, 11, 685-703. https://doi.org/10.1111/j.1582-4934.2007.00077.x

[30] Rooks, M.G. and Garrett, W.S. (2016) Gut Microbiota, Metabolites and Host Immunity. Nature Reviews Immunology, 16, 341-352. https://doi.org/10.1038/nri.2016.42

[31] Nowotarski, S.L., Woster, P.M. and Casero, R.A. Jr. (2014) Polyamines and Cancer: Implications for Chemoprevention and Chemotherapy. Expert Reviews in Molecular Medicine, 15, e3. https://doi.org/10.1017/erm.2013.3

[32] Chikindas, M.L., Weeks, R., Drider, D., Chistyakov, V.A. and Dicks, L.M. (2017) Functions and Emerging Applications of Bacteriocins. Current Opinion in Biotechnology, 4, 23-28.

[33] Walsh, C.J., Guinane, C.M., O’Toole, P. and Cotter, P.D. (2014) Beneficial Modulation of the Gut Microbiota. The FEBS Journal, 588, 4120-4130. https://doi.org/10.1016/j.febslet.2014.03.035

[34] Gillor, O., Nirgo, L.M. and Riley, M.A. (2005) Genetically Engineered Bacteriocins and Their Potential as the Next Generation of Antimicrobials. Current Pharmaceutical Design, 11, 1381-6128. https://doi.org/10.2174/1381612053381666

[35] Quintana, M.Q., Nicolas, T.I., Wachsman, M.B., Sinko, P.J., Castilla, V. and Chikindas, M. (2014) Anti Herpes Simplex Virus Type 2 Activity of the Antimicrobial Peptide Subtilosin. Journal of Applied Microbiology, 117, 1253-1259. https://doi.org/10.1111/jam.12618

[36] Turovskiy, Y., Ludescher, R.D., Aroutcheva, A.A., Faro, S. and Chikindas, M. (2009) Lactocin 160, a Bacteriocin Produced by Vaginal Lactobacillus Rhamnosus, Targets 
Cytoplasmic Members of the Vaginal Pathogen Gardnerella Vaginalis. Probiotics Antimicrob Proteins, 1, 67-74. https://doi.org/10.1007/s12602-008-9003-6

[37] Noll, K.S., Prichard, M.N., Khaykin, A., Sinko, P.J. and Chikindas, M.L. (2012) The Natural Antimicrobial Peptide Subtilosin Acts Synergistically with Glycerol Monolaurate, Lauric Arginate, and e-Poly-L-Lysine against Bacterial Vaginosis-Associated Pathogens but Not Human Lactobacilli. Antimicrob Agents Chemother, 56, 1756-1761. https://doi.org/10.1128/AAC.05861-11

[38] Rea, M.C., Sit, C.S., Clayton, E., O’Connor, P.M., Whittal R.M., Zheng, J., Vederas, J.C, Ross, R.P. and Hill, C. (2010) Thuricin CD, a Posttranslationally Modified Bacteriocin with a Narrow Spectrum of Activity against Clostridium Difficile. Proceedings of the National Academy of Sciences of the United States of America, 107, 9352-9357. https://doi.org/10.1073/pnas.0913554107

[39] Corr, S.C., Li, Y., Riedel, C.U., O’Toole, P.W., Hill, C. and Gahan, C.G. (2007) Bacteriocin Production as a Medium for the Antiinfective Activity of Lactobacillus Salivarius UCC118. Proceedings of the National Academy of Sciences of the United States of America, 104, 7617-7621. https://doi.org/10.1073/pnas.0700440104

[40] Svetoch, E., Eruslanov, B.V., Levchuk, V.P., Perelygin, V.Y., Mitsevich, E.V., Mitsevich, I.P., Stepanshin, J., Dyatlov, I., Seal, B.S. and Stern, N.J. (2011) Isolation of Lactobacillus salivaius (NRRL B-5003) and Characterization of Its Bacteriocin, Including the Antimicrobial Activity Spectrum. Applied and Environmental Microbiology, 77, 2749-2754. https://doi.org/10.1128/AEM.02481-10

[41] Akerey, B., Le-Lay, C., Fliss, I., Subirade, M. and Rouabhia, M. (2009) In Vitro Efficacy of Nisin Z against Candida Albicans Adhesion and Transition Following Contact with Normal Human Gingival Cells. Journal of Applied Microbiology, 107, 1298-1307. https://doi.org/10.1111/j.1365-2672.2009.04312.x

[42] Piper, C., Hill, C., Cotter, P.D. and Ross, R.P. (2011) Bioengineering of a Nisin A-Producing Lactobacillus Lactis to Create Isogenic Strains Producing the Natural Variants Nisin F, Q and Z. Microb Biotechnol, 4, 75-382. https://doi.org/10.1111/j.1751-7915.2010.00207.x

[43] Kwaadsteniet, M., VanReenan, C.A. and Dicks, L.M. (2010) Evaluation of Nisin F in the Treatment of Subcutaneous Skin Infections, as Monitored by Using a Bioluminescent Strain of Staphylococcus aureus. Probiotics Antimicrob Proteins, 2, 61-65. https://doi.org/10.1007/s12602-009-9017-8

[44] Shaikh, A.M. and Sreeja, V. (2017) Metabiotics and Their Health Benefits. International Journal of Food and Fermentation, 6, 11-23. https://doi.org/10.5958/2321-712X.2017.00002.3

[45] Lebeer, S., Vanderlevden, J. and Keersmaecker, C.J.D. (2008) Genes and Molecules of Lactobacilli Supporting Probiotic Action. Microbiology and Molecular Biology Reviews, 72, 728-764. https://doi.org/10.1128/MMBR.00017-08

[46] Sengul, N., Isik, S., Aslm, B., Ucer, G. and Demirbag, A.E. (2010) The Effect of Expolysaccharide-Producing Probiotic Strains on Gut Oxidative Damage in Experimental Colitis. Digestive Diseases and Sciences, 56, 707-714. https://doi.org/10.1007/s10620-010-1362-7

[47] Lenda, M.C., Nowak, B., Srottek, M., Gamian, A. and Marcinkiewicz, J. (2011) Immunoregulatory Potential of Exopolysaccharide from Lactobacillus Rhamnosus KL37. Effects on the Production of Inflammatory Mediators by Mouse Macrophages. International Journal of Experimental Pathology, 92, 382-391. https://doi.org/10.1111/j.1365-2613.2011.00788.x

[48] Surana, N.K. and Kasper, D.L. (2012) The Yin Yang of Bacterial Polysaccharides: 
Lessons Learned from B. fragilis PSA. Nature Reviews, 245, 13-26. https://doi.org/10.1111/j.1600-065X.2011.01075.x

[49] Matsuguchi, T., Takagi, A., Matsuzaki, T., Nagaoka, M., Ishikawa, K., Yokokura, T. and Yoshikal. Y. (2003) Lipoteichoic Acids from Lactobacillus Strains Elicit Strong Tumor Necrosis Factor Alpha-Inducing Activities in Macrophages through Toll Like Receptor 2. Clinical and Diagnostic Laboratory Immunology, 10, 259-266. https://doi.org/10.1128/CDLI.10.2.259-266.2003

[50] Huang, L., Shan, Y.J., He, C.X., Ren, M.H., Tian, P.J. and Song, W. (2015) Effects of L.paracasei subp. Paracasei X12 on Cell Cycle of Colon Cancer HT-29 Cells and Regulation of mTOR Signalling Pathway. Journal of Functional Foods, 21, 431-439. https://doi.org/10.1016/j.jff.2015.12.024

[51] Matsumoto, S. (2007) Anti Inflammatory Effects of Probiotic Lactobacillus Casei Strain Shirota in Chronic Intestinal Inflammatory Disorders. International Journal of Probiotics and Prebiotics, 3, 149-152.

[52] Yan, F., Cao, H., Cover, T.L., Whitehead, R., Washington, M.K. and Polk, D.B. (2007) Soluble Proteins Produced by Probiotic Bacteria Regulate Intestinal Epithelial Cell Survival and Growth. Gastroenterology, 132, 562-575. https://doi.org/10.1053/j.gastro.2006.11.022

[53] Wang, R., Jiang, L., Zhang, M., Zhao, L., Hao, Y., Guo, H., Sang, Y., Zhang, H. and Ren F. (2017) The Adhesion of Lactobacillus Salivarius REN to a Human Intestinal Epithelial Cell Line Requires S-layer Proteins. Scientific Reports, 7, 44209. https://doi.org/10.1038/srep44029

[54] Tripathi, P., Beaussart, A., Alsteens, D., Dupres, V., Claes, I., Von, O.I., de Vos, W.M., Palva, A., Lebeer, S., Vanderleyden, J. and Dufrene, Y.F. (2013) Adhesion and Nanomechanics of Pili from the probiotic Lactobacillus rhamnosus GG, ACS Nano, 7, 3685-3697. https://doi.org/10.1021/nn400705u

[55] Meyrand, M., Guillot, A., Goin, M., Furlan, S., Armalyte, J, Kulakauskas, S., Cortes-Perez, N.G., Thomas, G., Chat, S., Pechoux, C., et al. (2013) Surface Proteome Analysis of a Natural Isolte of Lactococcus Lactis Reveals the Presence of Pili Able to Bind Human Intestinal Epithelial Cells. Molecular \& Cellular Proteomics, 12, 3935-3947. https://doi.org/10.1074/mcp.M113.029066

[56] Pokusaeva, K., Johnson, C., Luk, B., Uribe, G., Oezguen, N., Matsunami, R.K., Lugo, M., Major, A., Mori-Akiyama, Y., Hollister, E.B., et al. (2016) GABA-Producing Bifidobacterium Dentium Modulates Visceral Sensitivity in the Intestine. Neurogastroenterology \& Motility, 29, e12904. https://doi.org/10.1111/nmo.12904

[57] Galland, L. (2014) The Gut Microbiome and the Brain. Journal of Medicinal Food, 17, 1261-1272. https://doi.org/10.1089/jmf.2014.7000

[58] O’Mahony, S.M., Clarke, G., Borre, Y.E., Dinan, T.G. and Cryan, J.E. (2014) Serotonin Tryptophan Metabolism and the Brain Gut Microbiome Axis. Behavioural Brain Research, 277, 32-48. https://doi.org/10.1016/j.bbr.2014.07.027

[59] Alkasir, R., Li, J., Li, X., Jin, M. and Zhu, B. (2016) Human Gut Microbiota: The Links with Dementia Development. Protein Cell, 8, 90-102.

https://doi.org/10.1007/s13238-016-0338-6

[60] Wall, R., Marques, T.M., O’Sullivan, O., Ross, R.P., Shanahan, F., Quigley, E.M, Dinan, T.G., Kiely, B., Fitzgerald, G.F., Cotter, P.D., Fouhy, F. and Stanton, C. (2012) Contrasting Effects of Bifidobacterium Breve Ncimb 702258 and Bifidobacterium Breve DPC 6330 on the Composition of Murine Brain Fatty Acids and Gut Microbiota. American Journal of Clinical Nutrition, 95, 1278-1287. https://doi.org/10.3945/ajcn.111.026435 
[61] Lee, Y. (2008) Isomer Specificity of Conjugated Linoleic Acid (CLA): 9E, 11E-CLA. Nutrition Research and Practice, 2, 326-330. https://doi.org/10.4162/nrp.2008.2.4.326

[62] Gaudier, E., Michel, C., Segain, J.P., Cherbu, C. and Hoebler, C. (2005) The VSL\#3 Probiotic Mixture Modifies Microflora but Does Not Heal Chronic Dextran-Sodium Sulfate-Induced Colitis or Reinforce the Mucus Barrier in Mice. Journal of Nutrition, 135, 2753-2761. https://doi.org/10.1093/jn/135.12.2753

[63] Dow, J.M. (2017) Diffusible Signal Factor-Dependent Quorum Sensing in Pathogenic Bacteria and Its Exploitation for Disease Control. Journal of Applied Microbiology, 122, 2-11. https://doi.org/10.1111/jam.13307

[64] Jacobi, C.A., Grundler, S., Hsieh, C.J., Frick, J.S., Adam, P., Lamprecht, G., Autenrieth, I.B., Gregor, M. and Malfertheiner, P. (2012) Quorum Sensing in the probiotic Bacterium Escherichia Coli Nissle 1917 (Mutaflor)-Evidence That Furanosyl Borate Diester (AL-2) Is Influencing the Cytokine Expression in the DSS Colitis Mouse Model. Gut Pathogens, 4, 8. https://doi.org/10.1186/1757-4749-4-8

[65] Buck, B.L., Azcarate-Peril, M.A., Klaenhammer, T.R. (2008) Role of Autoinducer-2 on the Adhesion Ability of Lacobacillus Acidophilus. Journal of Applied Microbiology, 107, 269-279. https://doi.org/10.1111/j.1365-2672.2009.04204.x

[66] Mitsuma, T., Odajima, H., Momiyama, Z., Watanabe, K., Masuguchi, M., Sekine, T., Shidara, S. and Hirano, S. (2007) Enhancement of Gene Expression by a peptide P (CHWPR) Produced by Bifidobacterium Lactis BB-12. Microbiology and Immunology, 52, 144-155. https://doi.org/10.1111/j.1348-0421.2008.00022.x

[67] Jenabian, S.M., Vogensen, F.K. and Jespersen, L. (2011) The Quorum Sensing luxS Is Induced in Lactobacillus acidophilus NCFM in Response to Listeria monocytogenes. International Journal of Food Microbiology, 149, 269-273. https://doi.org/10.1016/j.ijfoodmicro.2011.06.011

[68] Li, S., Bostick, J.W. and Zhou, L. (2017) Regulation of Innate Lymphoid Cells by Aryl Hydrocarbon Receptor. Frontiers Immunology, 8, 1909-1921. https://doi.org/10.3389/fimmu.2017.01909

[69] Li, S. and Heller, J.J. (2016) Ikaros Inhibits Group 3 Innate Lymphoid Cell Development and Function by Suppressing the Aryl Hydrocarbon Receptor Pathway. Immunity, 45, 185-197. https://doi.org/10.1016/j.immuni.2016.06.027

[70] Zelante, T., Iannitti, R.G., Cunha, C., Luca, A.D., Giovannini, G., Pieraccini, G., Zecchi, R., D’Angelo, C., Benedetti, C.M., Fallarino, F., et al. (2013) Tryptophan Catabolites from Microbiota Engage Aryl Hydrocarbon Receptor and Balance Mucosal Reactivity via Interleukin-22. Immunity, 39, 372-385.

https://doi.org/10.1016/j.immuni.2013.08.003

[71] Kim, M. and Kim, C.H. (2016) Colonization and Effector Functions of Innate Lymphoid Cells in Mucosal Tissues. Microbes and Infection, 18, 604-614. https://doi.org/10.1016/j.micinf.2016.06.005

[72] Moller, N.P., Elisabeth, K., Ahrens, S., Roos, N. and Schrezmeir, J. (2008) Bioactive Peptides and Proteins from Foods: Indication for Health Effects. European Journal of Nutrition, 47, 171-182. https://doi.org/10.1007/s00394-008-0710-2

[73] Albenzio, M., Santillo, A., Carprese, M., Malva, A.D. and Marino, R. (2017) Bioactive Peptides in Animal Food Products. Foods, 6, 1-14.

[74] Bauchart, C. and Remond, D. (2006) Small Peptides $(<5 \mathrm{kDa})$ Found in Ready-to-Eat Beef Meat. Meat Science, 74, 658-666. https://doi.org/10.1016/j.meatsci.2006.05.016 
[75] Fu, Y. and Young, J.F. (2017) Bioactive Peptides in Beef: Endogenous Generation through Postmortem Aging. Meat Science, 123, 134-142. https://doi.org/10.1016/j.meatsci.2016.09.015

[76] Korhonen, H. and Leppala, A.P. (1998) Impact of Processing on Bioactive Proteins and Peptides. Trends in Food Science and Technology, 9, 307-319. https://doi.org/10.1016/S0924-2244(98)00054-5

[77] Arihara, K. (2006) Strategies for Designing Novel Functional Meat Products. Meat Science, 74, 219-229. https://doi.org/10.1016/j.meatsci.2006.04.028

[78] Katayama, K., Anggraeni, H.E., Mori, T., Ahhmed, A.M., Kawahara, S., Suglyama, M., Nakayama, T., Maruyama, M. and Muguruma, M. (2008) Porcine Skeletal Muscle Troponin Is a Good Source of Peptides with Angiotensin-I Converting Enzyme Inhibitory Activity and Antihypertensive Effects in Spontaneously Hypertensive Rats. Journal of Agricultural and Food Chemistry, 56, 355-360. https://doi.org/10.1021/jf071408j

[79] Escudero, E. and Sentandreu, M.A. (2010) Angiotensin I-Converting Enzyme Inhibitory Peptides Generated from in Vitro Gastrointestinal Digestion of Pork Meat. Journal of Agricultural and Food Chemistry, 58, 2895-2901. https://doi.org/10.1021/jf904204n

[80] LeaBlanc, J.G., Milani, C., de Glori, G.S., Sesma, F., van Sinderen, D. and Ventura, M. (2013) Bacteria as Vitamin Suppliers to Their Host: A Gut Microbiota Perspective. Current Opinion in Biotechnology, 24,160-168. https://doi.org/10.1016/j.copbio.2012.08.005

[81] Biesalski, H.K. (2016) Nutrition Meets the Microbiome: Micronutrients and the Microbiota. Annals of the New York Academy of Sciences, 1372, 53-64. https://doi.org/10.1111/nyas.13145

[82] Pompei, A., Cordisco, L., Zanoni, S., Matteuzzi, D. and Rossi, M. (2007) Folate Production by Bifidobacteria as a Potential Probiotic Property. Applied and Environmental Microbiology, 73, 179-185. https://doi.org/10.1128/AEM.01763-06

[83] Taylor, S.O., Robert, E.W., James, L.S. and Jeff, R.B. (2012) Identification of Plasmalogens in the Cytoplasmic Membrane of Bifidobacterium Animalis subsp. Lactis. Applied and Environmental Microbiology, 78, 880-884. https://doi.org/10.1128/AEM.06968-11

[84] Murphy, E.J., Schapiro, M.B., Rapoport, S.I. and Shetty, H.U. (2000) Phospholipid Composition and Levels Are Altered in Down Syndrome Brain. Brain Research, 867, 9-18. https://doi.org/10.1016/S0006-8993(00)02205-8

[85] Han, X., Holtzman, D.M. and Mckeel, Jr D.W. (2011) Plasmologen Deficiency in Early in Early Alzheimer's Disease Subjects and in Animal Models: Molecular Characterization Using Electrospray Ionization Mass Spectrometry. Journal of Neurochemistry, 77, 1168-1180. https://doi.org/10.1046/j.1471-4159.2001.00332.x

[86] Singh, I., Paintilla, A.S., Khan M. and Contreras, M.A. (2004) Impaired Peroxisomal Function in the Central Nervous System with Inflammatory Disease of Experimental Autoimmune Encephalomyelitis Animals and Protection by Lovastin Treatment. Brain Research, 1022, 1-11. https://doi.org/10.1016/j.brainres.2004.06.059

[87] Fabelo, N., Martin, V., Sanntpere, G., Marln, R., Torrent, L., Ferrer, I. and Diaz, M. (2011) Severe Alteration in Lipid Composition of Frontal Cortex Lipid Rafts from Parkinson's Disease and Incidental Parkinson's Disease. Molecular Medicine, 17, 1107-1118. https://doi.org/10.2119/molmed.2011.00119

[88] Wang, Q.C., Nie, Q.H. and Feng, Z.H. (2003) RNA Interference: Antivral Weapon and Beyond. World Journal of Gastroenterology, 9, 1657-1661. 
https://doi.org/10.3748/wjg.v9.i8.1657

[89] Sharma, M. and Shukla, G. (2016) Metabiotics: One Step Ahead of Probiotics; an Insight into Mechanisms Involved in Anticancerous Effect in Colorectal Cancer. Frontiers in Microbiology, 7, 1940. https://doi.org/10.3389/fmicb.2016.01940

[90] Barrett, E., Ross, R.P., O’Toole, P.W., Fitzgerald, G.F. and Stanton, C. (2012) Gamma-Aminobutyric Acid Production by Culturable Bacteria from the Human Intestine. Journal of Applied Microbiology, 113, 411-441. https://doi.org/10.1111/j.1365-2672.2012.05344.x

[91] Shishov, V.A., Kirovskaia, T.A., Kudrin, V.S. and Oleskin, A.V. (2009) Amine Neuromediators, Their Precursors, and Oxidation Products in the Culture of Escherichia coli K-12. Applied Biochemistry and Microbiology, 45, 550-554.

[92] Özogul, F. (2011) Effects of Specific Lactic Acid Bacteria Species on Biogenic Amine Production by Foodborne Pathogen. International Journal of Food Science \& Technology, 46, 478-484. https://doi.org/10.1111/j.1365-2621.2010.02511.x

[93] Tsavkelova, E.A., Botvinko, I.V., Kudrin, V.S. and Oleskin, A.V. (2000) Detection of Neurotransmitter Amines in Microorganisms with the Use of High-Performance Liquid Chromatography. Doklady Biochemistry, 372, 115-117.

[94] Marquardt, P. and Spitznagel, G. (1959) Bakterielle Acetylcholine Bildung in Kunstlichen Nahrboden. Arzneimittelforschung, 9, 456-465.

[95] Kawashima, K., Misawa, H., Moriwaki, Y, Fujii, Y.X., Fujii, T., Horiuchi, Y., Yamada, T., Imanaka, T. and Kamekura, M. (2007) Ubiquitous Expression of Acetylcholine and Its Biological Functions in Life Forms without Nervous Systems. Life Sciences, 80, 2206-2209. https://doi.org/10.1016/j.lfs.2007.01.059

[96] Landete, J.M., De las Rivas, B., Marcobal, A., and Munoz, R. (2008) Updated Molecular Knowledge about Histamine Biosynthesis by Bacteria. Critical Reviews in Food Science and Nutrition, 48, 697-714. https://doi.org/10.1080/10408390701639041

[97] Thomas, C.M., Hong T., Van Pijkeren J.P, Hemarajata, P., Trinh D.V., Hu W., Britton R.A., Kalkum, M. and Versalovic, J. (2012) Histamine Derived from Probiotic Lactobacillus Reuteri Suppresses TNF via Modulation of PKA and Erk Signaling. PLoS One, 7, e31951. https://doi.org/10.1371/journal.pone.0031951

[98] Jellet, J.J., Forrest, T.P., Macdonald, I.A., Marrie, T.J. and Holdeman, L.V. (1980) Production of indole-3-propanoic Acid and 3-(p-hydroxyphenyl) Propanoic Acid by Clostridium Sporogenes: a Convenient Thin-Layer Chromatography Detection System. Canadian Journal of Microbiology, 26, 448-453. https://doi.org/10.1139/m80-074

[99] Bendheim, P.E, Poeggeler, B, Neria, E, Ziv, V., Pappolla, M.A. and Chain, D.G. (2002) Development of indole-3-propionic acid (OXIGON) for Alzheimer's Disease. Journal of Molecular Neuroscience, 19, 213-217. https://doi.org/10.1007/s12031-002-0036-0

[100] Russell, W.R., Hoyles, L., Flint, H.J, and Dumas, M.E. (2013) Colonic Bacterial Metabolites and Human Health. Current Opinion in Microbiology, 16, 246-254. https://doi.org/10.1016/j.mib.2013.07.002

[101] Bradley, W.G. and Mash, D.C. (2009) Beyond Guam: the Cyanobacteria/BMAA Hypothesis of the Cause of ALS and Other Neurodegenerative Diseases. Amyotrophic Lateral Sclerosis, 10, 7-20. https://doi.org/10.3109/17482960903286009

[102] Levi, M., Keller, T.T., van Gorp, E. and ten Cate, H. (2003) Infection and inflammation and the Coagulation System. Cardiovascular Research, 60, 26-39. https://doi.org/10.1016/S0008-6363(02)00857-X 
[103] Wang, X. and Quinn, P.J. (2010) Endotoxins: Lipopolysaccharides of Gram-Negative Bacteria. Subcellular Biochemistry, 53, 3-25. https://doi.org/10.1007/978-90-481-9078-2_1

[104] Vuong, H.E. and Hsiao, E.Y. (2016) Emerging Roles for the Gut Microbiome in Autism Spectrum Disorder. Biological Psychiatry, 81, 411-423.

https://doi.org/10.1016/j.biopsych.2016.08.024

[105] Hsiao, E.Y., McBride, S.W., Hsien S., Sharon, G., Hyde, E.R., McCue T., Codelli J.A, Chow, J., Reisman, S.E., Petrosino, J.F., Patterson, P.H. and Mazmanian, S.K. (2013) Microbiota Modulates Behavioral and Physiological Abnormalities Associated with Neurodevelopmental Disorder. Cell, 155, 1451-1463. https://doi.org/10.1016/j.cell.2013.11.024

[106] Petra, L. (2012) Does the Human Gut Microbiota Contribute to the Etiology of Autism Spectrum Disorders? Digestive Diseases and Sciences, 57, 1987-1989. https://doi.org/10.1007/s10620-012-2286-1

[107] Foster, J.A. and Neufeld, K.A.M. (2013) Gut-Brain Axis: How the Microbiome Influences Anxiety and Depression. Trends in Neurosciences, 36, 305-312. https://doi.org/10.1016/j.tins.2013.01.005

[108] Reid, G., Abrahamsson, T., Bailey, M., Bindels, L.B., Bubnov, R., Ganguli, K., Martoni, C., O’Neill, C., Savignac, H.M., Stanton, C., et al. (2017) How Do Probiotics and Prebiotics Function at Distant Sites? Beneficial Microbes, 8, 521-533. https://doi.org/10.3920/BM2016.0222

[109] Dinan, T.G. and Cryan, J.F. (2013) Melancholic Microbes: A Link between Gut Microbiota and Depression? Neurogastroenterology \& Motility, 25, 713-719. https://doi.org/10.1111/nmo.12198

[110] Proctor, C., Thiennimitr, P., Chattipakorn, N., Chattipakorn, S.C. (2017) Diet, Gut Microbiota and Cognition. Metabolic Brain Disease, 32, 1-17. https://doi.org/10.1007/s11011-016-9917-8

[111] Hu, X., Wang, T., Jin, F. (2016) Alzheimer's Disease and Gut Microbiota. Science China Life Sciences, 59, 1006-1023.

[112] Reitz, C. (2011) Epidemiology of Alzheimer Disease. Nature Reviews Neurology, 7, 137-152. https://doi.org/10.1038/nrneurol.2011.2

[113] Dragicevic, N., Copes, N., O’Neal-Moffitt, G., Jin, J., Buzzeo, R., Mamcarz, M., tan, J., Cao, C., Olcese, JM., Arendash, G.W. and Bradshaw, P.C. (2011) Melatonin Treatment Restores Mitochondrial Function in Alzheimer's Mice: A Mitochondrial Protective Role of Melatonin Membrane Receptor Signaling. Journal of Pineal Research, 51, 75-86. https://doi.org/10.1111/j.1600-079X.2011.00864.x

[114] Westfall, S., Lomis, N., Singh, S.P., Dal, S.Y. and Prakash, S. (2015) The Gut Microflora and Its Metabolites Regulate the Molecular Crosstalk between Diabetes and Neurodegeneration. Journal of Diabetes and Metabolism, 6, 8.

[115] Scott, L., Dawson, V.L. and Dawson, T.M. (2017) Trumping Neurodegeneration: Targetting Common Pathways Regulated by Autosomal Recessive Parkinson's Disease Genes. Experimental Neurology, 298, 191-201.

[116] Mulak, A. and Bonaz, B. (2015) Brain-Gut-Microbiota Axis in Parkinson's Disease. World Journal of Gastroenterology, 21, 10609-10620. https://doi.org/10.3748/wjg.v21.i37.10609

[117] Bian, L., Nagata, S, Takashi, R., Mohammed S., Ohta, T., Yuki, N., Wang, C., Takano, K., Daibo, M., Momoto, K. and Yamashiro, Y. (2011) Effects of the Continuous intake of Lactobacillus Caesi Strain Shirota-Fermented Milk on Risk Management of Long Term Inpatients at Health Service Facilities for the Elderly. International 
Journal of Probiotics and Prebiotics, 6, 123-132.

[118] Bach, J.F. (2002) The effect of Infections on Susceptibility to Autoimmune and Allergic Diseases. The New England Journal of Medicine, 347, 911-920. https://doi.org/10.1056/NEJMra020100

[119] Rook, G.A.W. and Brunet, L.R. (2005) Microbes, Immunoregulation, and the Gut. Journal of Medical Genetics, 54, 317-320. https://doi.org/10.1136/gut.2004.053785

[120] Campbell, A.W. (2014) Autoimmunity and Gut. Autoimmune Diseases, 2014, 12. https://doi.org/10.1155/2014/152428

[121] Wu, X., He, B., Liu, J., Feng, H., Li, D., Guo, B., Liang, C., Dang, L., Wang, L., Tian, J., et al. (2016) Molecular Insight into the Gut Microbiota and Rheumatoid Arthritis. International Journal of Molecular Sciences, 17, 43. https://doi.org/10.3390/ijms17030431

[122] Mu, Q., Zhang, H. and Luo, X.M. (2015) SLE: Another Autoimmune Disorder Influenced by Microbes and Diet? Frontiers in Immunology, 6, 608. https://doi.org/10.3389/fimmu.2015.00608

[123] Lavasani, S., Dzhambazov, B., Nouri, M., Fak F., Buske, S., Molin, G., Thorlacius, H., Alenfall, J., Jeppsson, B. and Westrom, B. (2010) A Novel Probiotic Mixture Exerts a Therapeutic Effect on Experimental Autoimmune Encephalomyelitis MEDiated by IL-10 Producing Regulatory T Cells. PloS One, 5, e9009. https://doi.org/10.1371/journal.pone.0009009

[124] Qiu, X., Zhang, M., Yang, X., Hong, N. and Yu, C. (2013) Faecalibacterium Prausnitzii Upregulates Regulatory T Cells and Anti-Inflammatory Cytokines in Treating TNBS-Induced Colitis. Journal of Crohn's and Colitis, 7, e558-568. https://doi.org/10.1016/j.crohns.2013.04.002

[125] So, J.S., Kwon, H.K., Lee, C.G., Yi, H.J., Park, J.A., Lim, S.Y., Hwang, K.C., Jeon, Y.H. and Im, S.H. (2008) Lactobacillus Caesi Suppresses Experimental Arthritis by Down-Regulating $\mathrm{T}$ Helper 1 Effecter Functions. Molecular Immunology, 45, 2690-2699. https://doi.org/10.1016/j.molimm.2007.12.010

[126] Hatakka, K., Martio, J., Korpela, M., Herranen, M., Poussa, T., Laasanen, T., Saxelin, M., Vapaatalo, H., Moilanen, E. and Korpela, R. (2003) Effects pf Probiotic Therapy on the Activity and Activation of Mild Rheumatoid Arthritis-A Pilot Study. Scandinavian Journal of Rheumatology, 32, 211-215. https://doi.org/10.1080/03009740310003695

[127] Bischoff, S.C., Boirie, Y., Cederholm, T., Chourdakis, M., Cuereda, C., Delzenne, N.M., Deutz, N.E., Fouque, D., Genton, L. and Gil, C., et al. (2017) Towards a Multidisciplinary Approach to Understand and Manage Obesity and Related Diseases. Clinical Nutrition, 36, 917-938. https://doi.org/10.1016/j.clnu.2016.11.007

[128] Ichimura, A., Hasegawa, S., Kasubuchi, M. and Kimura, I. (2014) Free Fatty Acid Receptors as Therapeutic Targets for the Treatment of Disease. Frontiers in Pharmacology, 5, 00236. https://doi.org/10.3389/fphar.2014.00236

[129] Esgalhado, M., Kemp, J.A., Damasceno, N.R.T., Fogue, D. and Mafra, D. (2017) Short-Chain Fatty Acids: A Link between Prebiotics and Microbiology. Future Microbiology, 12, 23-29.

[130] Pais, R., Gribble, F.M. and Reimann, F. (2016) Stimulation of Incretin Secreting Cells. Advances in Endocrinology and Metabolism, 7, 24-42. https://doi.org/10.1177/2042018815618177

[131] Stenman, L.K., Wage, A., Garret, C., Kiopp, P., Burcelin, R. and Lahtinen, S. (2014) Potential Probiotic Bifidobacterium Animalis ssp. Lactis Prevents Weight Gain and 
Glucose Intolerance in Diet-Induced Obese Mice. Beneficial Microbes, 5, 437-445. https://doi.org/10.3920/BM2014.0014

[132] Takahashi, S., Anzawa, D., Takami, K., Ishizuka, A., Mawatari, T., Kamikado, K., Sugimura, H. and Nishijima, T. (2016) Effect of Bifidobacterium Animalis spp. Lactis GCL2505 on Visceral Fat Accumulation in Healthy Japanese Adults: A Randomized Controlled Trial. Bioscience of Microbiota, Food and Health, 35, 163-171. https://doi.org/10.12938/bmfh.2016-002

[133] Puddu, A., Sanguineti, R., Montecucco, F. and Viviani, G.L. (2014) Evidence for the Gut Microbiota Short Chain Fatty Acids as Key Pathophysiological Molecules Improving Diabetes. Mediators of Inflammation, 9, 1-9.

[134] Aronsson, L., Huang, Y., Parini, P., Korach-Andre, M., Gustafsson, J.A., Pettersson, S., Arulampalam, V. and Rafter, J. (2010) Decreased Fat Storage by lactobacillus Paracaesi Is Associated with Increased Levels of Angiopoietin-Like 4 Protein (ANGPTL4). Plos One, 5, e13087. https://doi.org/10.1371/journal.pone.0013087

[135] Peng, L., Li, Z.R., Green, R.S., Holzman, I.R. and Lin, J. (2009) Butyrate Enhances the Intestinal Barrier by Facilitating Tight Junction Assembly via Activation of AMP-Activated Protein Kinase in Caco-2 Cell Monolayers. The Journal of Nutrition, 139, 1619-1925. https://doi.org/10.3945/jn.109.104638

[136] Musso, G., Gambino, R. and Cassader, M. (2010) Obesity, Diabetes, and Gut Microbiota: The Hygiene Hypothesis Expanded? Diabetes Care, 33, 2277-2284. https://doi.org/10.2337/dc10-0556

[137] Begley, M., Hill, C. and Gahan, C.G.M. (2006) Bile Salt Hydrolase Activity in Probiotics. Applied and Environmental Microbiology, 72, 729-1738. https://doi.org/10.1128/AEM.72.3.1729-1738.2006

[138] Yoo, J.Y. and Kim, S.S. (2016) Probiotics and Prebiotics: Present Status and Future Perspectives on Metabolic Disorders. Nutrients, 8, 173. https://doi.org/10.3390/nu8030173

[139] Ettinger, G., MacDonald, K., Reid, G. and Burtaon, J.P. (2014) The Influence of the Human Microbiome and Probiotics on Cardiovascular Health. Gut Microbes, 5, 719-728. https://doi.org/10.4161/19490976.2014.983775

[140] Zhang, J., Deng, Z., Liao, J., Song, C., Liand, C., Xue, H., Wang, L., Zhang, K. and Yan, G. (2013) Leptin Attenuates Cerebral Ischemia Injury through the Promotion of Energy Metabolism via the PI3K/Akt Pathway. The Journal of Cerebral Blood Flow \& Metabolism, 33, 567-574. https://doi.org/10.1038/jcbfm.2012.202

[141] Shakeria, M., Razavi, S.H., Ziai, S.A., Khodaiyan, F., Yarmand, M.S. and Moayedi, A. (2015) Proteolytic and ACE-Inhibitory Activities of Probiotic Yogurt Containing On-Viable Bacteria as Affected by Different Levels of Fat, Inulin and Starter Culture. Journal of Food Science and Technology, 52, 2428-2433. https://doi.org/10.1007/s13197-013-1202-9

[142] Mahasneh, S.A. and Mahasneh, A.M. (2017) Probiotics: A Promising Role in Dental Health. Dentistry Journal, 5, 26. https://doi.org/10.3390/dj5040026

[143] Pandey, K.R., Naik, S.R. and Vakil, B.V. (2015) Prebiotics, Preiotics and Synbiotics-A Review. Journal of Food Science and Technology, 52, 7577-7587. https://doi.org/10.1007/s13197-015-1921-1

[144] Gupta, G. (2011) Probiotics and Periodontal Health. Journal of Medicine and Life, 4, 387-394.

[145] Bron, P.A., Kleerebezem, M., Brummer, R.J., Cani, P.D., Mercenier, A., MacDonald, T.T., Garcia-Rodenas, C.L. and Wells, J.M. (2017) Can Probiotics Modulate Human 
Disease by Impacting Intestinal Barrier Function? British Journal of Nutrition, 117, 93-107. https://doi.org/10.1017/S0007114516004037

[146] Helmy, Y.A., Kassem, II., Kumar, A. and Rajashekara, G. (2017) In Vitro Evaluation of the Probiotic E. coli Nissle 1917 on Campylobacter Jejuni's Invasion and Intracellular Survival in Human Colonic Cells. Frontiers in Microbiology, 8, 1588. https://doi.org/10.3389/fmicb.2017.01588

[147] Fitzpatrick, L.R. (2013) Probiotics for the Treatment of Clostridium Difficile Associated Disease. World Journal of Gastrointestinal Pathophysiology, 4, 47-52. https://doi.org/10.4291/wjgp.v4.i3.47

[148] Rea, M.C., Alemayehu, D., Casey, P.G., O’Connor, P.M., Lawlor, P.G., Walsh, M., Shanahan, F., Kiely, B., Ross, R.P. and Hill, C. (2014) Bioavailibility of the Anti-Clostridial Bacteriocin Thuricin CD in Gastrointestinal Tract. Microbiology, 160, 439-445. https://doi.org/10.1099/mic.0.068767-0

[149] Lee, A.S. and Song, K.P. (2005) LuxS/Autoinducer-2 Quorum Sensing Molecule Regulates Transcriptional Virulence in Clostridium Difficile. Biochemical and Biophysical Research Communications, 335, 659-666. https://doi.org/10.1016/j.bbrc.2005.07.131

[150] Mack, D.R., Michail, S., Wei, S., McDougall, L. and Hollingsworth, M.A. (1999) Probiotics Inhibit Enteropathogenic E. coli Adherence in Vitro by Inducing Intestinal Mucin Gene Expression. American Journal of Physiology, 276, G941-950.

[151] Roos, S. and Jonsson, H. (2002) A High Molecular-Mass Cell-Surface Protein from Lactobacillus Reuteri 1063 Adheres to Mucus Components. Microbiology, 148, 433-442. https://doi.org/10.1099/00221287-148-2-433

[152] Hirano, J., Yoshida, T., Sugiyama, T., Koide, N., Mori, I. and Yokochi, T. (2003) The Effect of Lactobacillus rhamnosus on Enterohemorrhagic Escherichia coli Infection of Human Intestinal Cells In Vitro. Microbiology and Immunology, 47, 405-409. https://doi.org/10.1111/j.1348-0421.2003.tb03377.x

[153] Homan, M. and Orel, R. (2015) Are Probiotics Useful in Helicobacter Pylori Eradication? World Journal of Gastroenterology, 21, 10644-10653. https://doi.org/10.3748/wjg.v21.i37.10644

[154] Roy, S. and Trincheri, G. (2017) Microbiota: A Key Orchestrator of Cancer Therapy. Nature Reviews Cancer, 17, 271-285. https://doi.org/10.1038/nrc.2017.13

[155] Licciardi, P.V., Wong, S.S, Tang, M.L. and Karagiannis, T.C. (2010) Epigenome Targeting by Probiotic Metabolites. Gut Pathogens, 2, 24.

https://doi.org/10.1186/1757-4749-2-24

[156] Kim, C.H., Park, J. and Kim, M. (2014) Gut Microbiota-Derived Short-Chain Fatty Acids, T Cells, and Inflammation. Immune Network, 14, 277-288.

https://doi.org/10.4110/in.2014.14.6.277

[157] Arpania, N., Campbell, C., Fan, X., Dikiy, S., VanDer Veeken, J., DeRoos, P., Liu, H., Cross, J.R., Pfeffer, K., Coffer, P.J. And Rudensky, A.Y. (2013) Metabolites Produced by Commensal Bacteria Promote Peripheral Regulatory T-Cell Generation. Nature, 504, 451-455. https://doi.org/10.1038/nature12726

[158] Park, K.Y., Li, G. and Platt, M.O. (2015) Monocyte-Derived Macrophage Assisted Breast Cancer Cell Invasion as a Personalized, Predictive Metric to Score Metastatic Risk. Scientific Reports, 5, 13855. https://doi.org/10.1038/srep13855

[159] Sepulveda, A.R., Yao, Y., Yan, W., Park, D.I., Kim, J.J., Gooding, W., Abudayyeh, S. and Graham, D.Y. (2010) CpG Methylation and Reduced Expression of O6-methylguanine DNA Methyltransferase Is Associated with Helicobacter pylori 
Infection. Gastroenterology, 138, 1836-1844.

https://doi.org/10.1053/j.gastro.2009.12.042

[160] Ding, S.Z. and Fischer, W., Kaparakis-Liaskos, M., Liechti, G., Merrell, S., Grant, P.A., Ferrero, R.L., Crowe, S.E., Haas, R., Hatakeyama, M. and Goldberg, J.B. (2010) Helicobacter Pylori-Induced Histone Modification, Associated Gene Expression in Gastric Epithlial Cells, and Its Implication in Pathogenesis. PLoS ONE, 5, e9875. https://doi.org/10.1371/journal.pone.0009875

[161] Medina, V., Edmonds, B., Young, G.P., James, R., Appleton, S. and Zalewski, P.D. (1997) Induction of Caspase-3 Protease Activity and Apoptosis by Butyrate and Trichostatin A (Inhibitors of Histone Deacetylase): Dependence on Protein Synthesis and Synergy with a Mitochondrial/Cytochrome c-dependent Pathway. Cancer Research, 57, 3697-707.

[162] Archer, S.Y., Meng, S., Shei, A. and Hodin, R.A. (1998) p21WAF1 Is Required for Butyratr-Mediated Growth Inhibition of Human Colon Cancer Cells. Proceedings of the National Academy of Sciences of the United States of America, 95, 6791-6796. https://doi.org/10.1073/pnas.95.12.6791

[163] Hinnebusch, B.F., Meng, S., Wu, J.T., Archer, S.Y. and Hodin, R.A. (2002) Propionate as a Health-Promoting Microbial Metabolite in the Human Gut. Nutrition Reviews, 69, 245-258.

[164] Bordonaro, M., Lazarova, D.L. and Sartorelli, A.C. (2008) Butyrate and Wnt Signalling: A Possible Solution to the Puzzle of Dietary Fiber and Colon Cancer Risk? Cell Cycle, 7, 1178-1183. https://doi.org/10.4161/cc.7.9.5818

[165] Louis, P. and Flint, H.J. (2009) Diversity, Metabolism and Microbial Ecology of Butyrate-Producing Bacteria from the Human Large Intestine. FEMS Microbiology Letters, 294, 1-8. https://doi.org/10.1111/j.1574-6968.2009.01514.x

[166] Jan, G., Belzacq, A.S., Haouzi, D., Rouault, A., Metivier, D., Kroemer, G. and Brenner, C. (2002) Propionibacteria Induce Apoptosis of Colorectal Carcinoma Cells via Short-Chain Fatty Acids Acting on Mitochondria. Cell Death and Differentiation, 9 , 179-188. https://doi.org/10.1038/sj.cdd.4400935

[167] Lan, A., Lagadic-Gossmann, D., Leimaire, C., Brenner, C. and Jan, G. (2007) Acidic Extracellular $\mathrm{pH}$ Shifts Colorectal Cancer Cell Death from Apoptosis to Necrosis Upon Exposure to Propionate and Acetate, Major End-Products of the Human Probiotic Propionibacteria. Apoptosis, 12, 573-591. https://doi.org/10.1007/s10495-006-0010-3

[168] Hosseini, E., Grootaert, C., Verstraete, W. and Van de Wiele, T. (2011) Propionate as a Health-Promoting Microbial Metabolite in the Human Gut. Nutrition Reviews, 69, 245-258. https://doi.org/10.1111/j.1753-4887.2011.00388.x

[169] Maslowski, K.M., Vieira, A.T., Ng, A., Kranich, J., Sierro, F., Yu, D., Schilter, H.C., Rolph, M.S., Mackay, F., Artis, D., Xavier, R.J., Teixeaira, M.M. and Mackay, C.R. (2009) Regulation of Inflammatory by Gut Microbiota and Chhemoattractant Receptor GPR43. Nature, 41, 1282-1286. https://doi.org/10.1038/nature08530

[170] Liu, C.T., Chu, F.J., Chou, C.C. and Yu, R.C. (2011) Antiproliferative and Cytotoxic Effects of Cell Fractions and Exopolysaccharides from Lactobacillus caesi 01. Mutation Research: Genetic Toxicology and Environmental Mutagenesis, 721, 157-162. https://doi.org/10.1016/j.mrgentox.2011.01.005

[171] Narayanan, A., Baskaran, S.A., Amalaradjou, M.A. and Venkitanarayanan, K. (2015) Anticarcinogenic Properties of Medium Chain Fatty Acids on Human Colorectal, Skin and Breast Cancer Cells in Vitro. International Journal of Molecular Sciences, 16, 5014-5027. https://doi.org/10.3390/ijms16035014 
[172] Davis, C.D. and Milner, J.A. (2009) Gastrointestinal Microflora, Food Components and Colon Cancer Prevention. The Journal of Nutritional Biochemistry, 20, 743-752. https://doi.org/10.1016/j.jnutbio.2009.06.001

[173] Urbanska, A.M., Bhathena, J., Martoni, C. and Prakash, S. (2009) Estimation of the Potential Antitumor Activity of Microencapsulated Lactobacillus acidophilus Yogurt Formulation in the Attenuation of Tumorigenesis in Apc (Min/+) Mice. Digestive Diseases and Sciences, 54, 264-273. https://doi.org/10.1007/s10620-008-0363-2

[174] Uccello, M., Malaguarnera, G., Basile, F., D’agata, V., Malaguarnera, M., Bertino, G., Vacante, M., Drago, F. and Biondi, A. (2012) Potential Role of Probiotics on Colorectal Cancer Prevention. BMC Surgery, 12, S35. https://doi.org/10.1186/1471-2482-12-S1-S35

[175] Zanello, G., Meurens, F., Berri, M., Chevaleyre, C., Melo, S., Auclair, E. and Salmon, H. (2011) Saccharomyces Cerevisiae Decreases Inflammatory Responses Induced by F4+ Enterotoxigenic Escherichia coli I Porcine Intestinal Epithelial Cells. Veterinary Immunology and Immunopathology, 141, 133-138. https://doi.org/10.1016/j.vetimm.2011.01.018

[176] Kato, K., Kuhara, A., Yoneda, T., Inoue, T., Takao, T., Ohgami, T., Dan, L., Kuboyama, A., Kusunoki, S., Takeda, S. and Wake, N. (2011) Sodium Butyrate Inhibits the Self-Renewal Capacity of Endometrial Tumor Side-Population Cells by Inducing DNA Damage Responses. Molecular Cancer Therapeutics, 10, 1430-1439. https://doi.org/10.1158/1535-7163.MCT-10-1062

[177] Laurence, Z., Romain, D., Roberti, M.P., Routy, B. and Kroemer, G. (2017) Anticancer Effects of the Microbiome and Its Products. Nature Reviews Microbiology, 15, 465-478. https://doi.org/10.1038/nrmicro.2017.44

[178] Feldman, D., Zhao, X.Y. and Krishnan, A.V. (2000) Vitamin D and Prostate Cancer. Journal of Endocrinology, 141, 5-9. https://doi.org/10.1210/endo.141.1.7341

[179] Lamson, D.W. and Plaza, S.M. (2003) The Anticancer Effects of Vitamin K. Alternative Medicine Review, 8, 203-318.

[180] Okomoto, M., Oshikawa, T., Ohe, G., Nishikawa, H., Furuichi, S., Tano, T., Moriya, Y., Saito, M. and Sato, M. (2001) Severe Impairment of Anti-Cancer Effect of Lipoteichoic Acid-Related Molecules Isolated from a Penicillin-Killed Streptococcus pyogenes in Toll-Like Receptor 4-deficient Mice. International Immunopharmacology, 1, 1789-1795. https://doi.org/10.1016/S1567-5769(01)00103-5 


\section{Abbreviations}

4-NQO-4-nitroquinoline 1-oxide

AA-Amino acid

ACE-Angiotensin converting enzyme

AChR-Acetylcholine receptor

$\mathrm{AD}$-Alzheimer's disease

AHR-Aryl hydrocarbon receptor

AI-2-Autoinducer-2

ANGPTL4-Angiopoietin-like 4

ASD-Autism spectrum disorders

$\mathrm{A} \beta-\beta$ amyloid

$\mathrm{BSH}$ - Bile-salt hydrolase

Caco-2-Caucasian colon adenocarcinoma 2

CFS-Cell free supernatant

CIA-Collagen-induced arthritis

CLA-Conjugated Linoleic Acid

CVD-Cardiovascular disease

DCs-Dendritic cells

DHA-Docosahexaenoic acid

EAE-Experimental autoimmune encephalomyelitis

ECM-Extracellular matrix

EHEC-Enterohemorrhagic E. coli

EPS-Exopolysaccharides

FA-Fatty acid

FFAR_-Free fatty acid receptor

GABA $-\gamma$-aminobutyric acid

GI-Gastrointestine

GLP_Glucagon-like peptide

GPCR-G-protein-coupled receptors

GPR43-G-protein coupled receptor 43

HDAC-Histone deacetylases

HIV-Human immunodeficiency virus

HSPs-Heat shock proteins

IBD_-Inflammatory bowel disease

IEC-Intestinal epithelial cells

IL- Interleukin

ILC - Innate lymphoid cell

ILF-Intestinal lymphoid follicles

IPA-Indole-3-propionic acid

LAB - Lactic acid bacteria

LC-PUFA-Long chain polyunsaturated fatty acids

LMW-Low molecular weight

LPS-Lipopolysaccharides 
LTA-Lipoteichoic acids

MSG-Monosodium glutamate

MUC3-Mucin 3

NAFLD - Non-alcoholic fatty liver disease

NFT-Neurofibrallary tangles

NO-Nitric oxide

PD_Parkinson's disease

PG-Peptidoglycan

PPAR - Proliferator activated receptor

PSA-Polysaccharide A

PSPG-Polysaccharide-peptidoglycan complex

QS-Quorum sensing

RA-Rheumatoid arthritis

rDCs-Regulatory dendritic cells

SCFAs-Short-chain fatty acids

SLE-Systemic lupus erthrymatosus

SLP-Surface layer Proteins

SMOM-Small molecules microbes originated homeostasis

SP-Senile plaques

T1DM-Diabetes mellitus type 1

T2DM-Diabetes mellitus type 2

$\mathrm{T}_{\mathrm{H}}$-T-helper cells

TJP1-Tight Junction Protein 1

TLR-Toll-like receptors

ZO-Zonula occludens 